$\frac{37}{1-1120 \%}$ LA-8358-MS

Lh. 1482

Informal Report

Coprecal: Materials Accounting in the Modified Process

$\frac{0}{5}$
$\frac{5}{6}$
$\frac{0}{0}$
$\frac{2}{5}$
$\frac{2}{5}$

MASTER

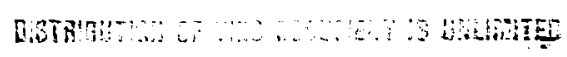

LOS ALAMO SCIENTIFIC LABORATORY

Post Office Box 1663 Los Alamo. New Mexico 87545 


\title{
Coprecal: Materials Accounting in the Modified Process
}

\author{
H. A. Dayem \\ E. A. Kern \\ J. P. Shipley
}
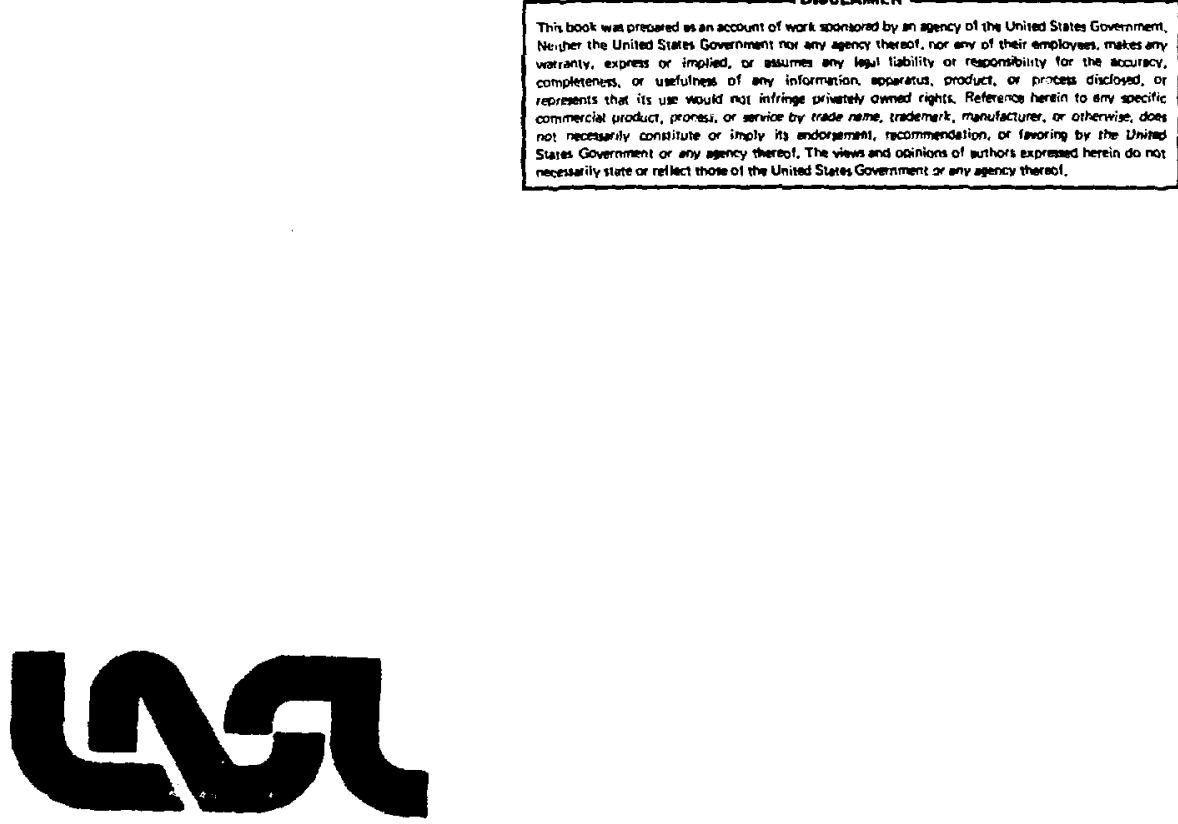
This study is the third in a series that considers the application of advanced materials accounting techniques to a uranium-plutonium nitrate-to-oxide coconversion facility based on the General Electric (GE) Coprecal process. The first study in the series identified several materials accountability problem areas; the most significant of these was the large absolute errors in the inventory measurements of the nine large feed-blend tanks at the head end of the process. The second study presented a preliminary assessment of the improvement in materials accountability in a Coprecal process that was modified by adding aliquot tanks to feed the process lines.

The original reference facility was designed by GE for the continuous coprecipitation and calcination of a blended uranium-plutonium-nitrate solution at the rate of $117 \mathrm{~kg}$ of plutonium per day. This amount includes $100 \mathrm{~kg}$ of plutonium product from a 10-tonne-per-day light-water reactor (LWR) fuels reprocessing facility and 17 $\mathrm{kg}$ of plutonium (as a uranium-plutoniumnitrate solution) from scrap recovery. The Coprecal process has been demonstrated in laboratory-scale equipment and extrapolated to production-scale equipment with many process and design assumptions.

This report describes the complete design and evaluation of an advanced materials measurement and accounting system for the Coprecal process as further modified by Savannah River Laboratory and Plant and dupont Engineering. Four modifications most significant for materials accounting are:
- Adding twelve aliquot tanks to feed the coconversion process lines.

- Adding a single primary and a single secondary filter to each calciner to replace the primary and secondary filters previously manifolded to four calciners. Each new filter is approximately half the size of the original filter.

- Raising the calciner operating temperature from $400^{\circ} \mathrm{C}$ to a range of $500^{\circ}-600^{\circ} \mathrm{C}$.

- Raising the reduction-stabilization operating temperature from a range of $550^{\circ}-650^{\circ} \mathrm{C}$ to as high as $800^{\circ} \mathrm{C}$.

The safeguards systems for both the original and the modified Coprecal process depend on an intelligent combination of conventional and near-real-time accounting techniques and on the ability to make suitable measurements of the nuclear material as it is being processed. The following conclusions can be drawn from a comparison of the measurements required for the original design with the measuremerts required for the modified design:

- Adding aliquot tanks improves the measurement system because measurement errors on small tanks are smaller than errors on large tanks.

- Adding aliquot tanks to feed the precipitator precludes the need for flow measurements of the precipitator feed streams.

- Adding independent filters to each calciner requires an additional neutron counter for each filter. 
- Adding independent filters to each calciner changes the materials accounting logic, requiring the addition of reduction-container level measurements.

- Adding independent filters to each calciner may increase neutron "cross-talk" between vessels within the calciner system, thus degrading measurement quality.

- Increasing operating temperatures in the calciner and the reductionstabilization stations may make holdup measurements in these vessels more difficult because instruments will have to operate at higher temperatures or be placed further from the measurement source.

Allowing for these restrictions, nearreal-time materials accounting strategies were developed and evaluated. Detection sensitivities for the modified coprecal process, the original Coprecal process, and the oxalate (III) conversion process are given in the Table. The detection sensitivities in each case are for the accounting strategy that includes an entire process line in a single accounting area. The process lines have the same throughput.

In comparing the detection sensitivities of the modified and original coprecal processes, note that:
1) The single-balance detection sensitivity for the modified process is not as good as the original process because the in-process inventory in the nodified process is larger. The inventory is larger because a filter system was added for each calciner.

2) Detection sensitivities for accounting periods greater than 1 day were improved in the modified process because the input transfer measurements were improved by adding aliquot tanks.

In comparing the detection sensitivities of the modified Coprecal process with the oxalate (III) conversion process, note that detection sensitivities for oxalate (III) are significantly better for all accounting periods. There are two reasons for this: (1) the in-process inventory in the oxalate (III) process is smaller; and (2) there are no scrap or vacuum measurements in the oxalate (III) process; these measurements contribute significantly to the materials balance uncertainty.

The following recommendations are essential for effective dynamic materials accountability in the modified coprecal process.

TABLE

DETECTION SENSITIVITY COMPARISON--

MODIFIED COPRECAL, ORIGINAL COPRECAL, OXALATE (III)

\begin{tabular}{|c|c|c|c|c|c|c|}
\hline \multirow[b]{2}{*}{$\begin{array}{l}\text { Detection } \\
\text { Time }\end{array}$} & \multicolumn{2}{|c|}{ Modified Coprecal } & \multicolumn{2}{|c|}{ Original Coprecal } & \multicolumn{2}{|c|}{ Oxalate (III) } \\
\hline & $\begin{array}{c}\text { Average per } \\
\text { Balance (4 h) } \\
\text { (kg Pu) } \\
\end{array}$ & $\begin{array}{l}\text { Total at } \\
\text { Detection } \\
\text { (kg Pu) }\end{array}$ & $\begin{array}{c}\text { Average per } \\
\text { Balance }(2 \mathrm{~h}) \\
(\mathrm{kg} \text { pu }) \\
\end{array}$ & $\begin{array}{l}\text { Total at } \\
\text { Detection } \\
\text { (kg pu) }\end{array}$ & $\begin{array}{c}\text { Average per } \\
\text { Balance }(1.3 \mathrm{~h}) \\
\text { (kg Pu) }\end{array}$ & $\begin{array}{l}\text { Total at } \\
\text { Detection } \\
\text { (kg Pu) } \\
\end{array}$ \\
\hline 1 balance & 1.4 & 1.4 & 1.2 & 1.2 & 0.4 & 0.4 \\
\hline 1 day & 0.27 & 1.6 & 0.13 & 1.6 & 0.02 & 0.5 \\
\hline I wk & 0.07 & 3.0 & 0.04 & 3.7 & 0.01 & 1.7 \\
\hline 1 month & 0.04 & 6.1 & 0.03 & 8.4 & 0.007 & 3.9 \\
\hline
\end{tabular}


- Measurement control programs that identify and control the sources of error must be instituted. If correlated errors in transfer measurements are not controlled, then the detection sensitivities will be unacceptably degraded.

- Provision must be rade for measuring the plutoniam in-process inventory in process equipment. In.. process inventory measurement precision should be $10 \%$ or better.

- Large neutron detection systems for measuring the plutonium inventory in process vessels and in large, annular filters should be built and demonstrated.
- Careful consideration should be given to reducing the in-process inventory.

- Methods of decreasing the amount of generated scrap should be investigated. Measurements of scrap could probably be improved if the Inconel shot is retained within the calciners.

- Consideration should be given to adding a precipitator to feed each calciner. This would provide a better process fiducial for taking materials balances. 
CONTENTS

I. INTRODUCTION. . . . . . . . . . . . . . 1

II. THE REFERENCE COCONVERSION FACILITY . . . . . . . . 1

A. The Major Modifications . . . . . . . . . . . 1

B. The Modified Process. .......... 3

III. MATERIALS MEASUREMENT AND ACCOUNTING SYSTEM . . - . 6

A. Measur ements. . . . . . . . . . . . . 7

B. Dynamic Materials Accounting Strategies: : : 10

1. Strategy 1 - UPAA $23 \mathrm{~A}, 23 \mathrm{~B}$, and $23 \mathrm{C}$. 11

2. Strategy 2. ................ 11

a. UPAA 2 A, 2 B, 2 C. . . . . . . . 12

b. UPAA 3 A, 3 B, 3 C. . . . . : : 12

IV. MODELING, SIMULATION, AND ANALYSIS TEChNIQUES . - . 12

A. Modeling and Simulation Approach. . . . : : 12

1. Process Model . . . . . . . . . . . . 12

2. Measurement Models. . . . . . . . . 12

3. Materials Balances. . . . . . . . . 13

B. Data Analysis Techniques. . . . . . . . . . 13

C. Data Inalysis Graphic Aids--Alarm Charts. . . 14

D. Systems Per formance Analysis. . . . . . . 14

v. EFFECTIVENESS EVALUATION. . . . . . . . . . 15

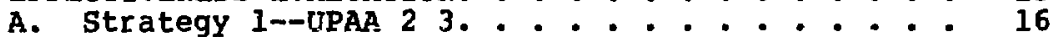

B. Strategy 2.................. 18

1. UPAA 2 A, 2 B, 2 C. . . . . . . . . . . . . 19

2. UPAA 3 A, 3 B, 3 C............ 19

VI. CONClusions . . . . . . . . . . . . . . . . 20

ACKNOWLEDGMENTS ................... 23

REFERENCES. . . . . . . . . . . . . . . . . 23

APPENDIX. . . . . . . . . . . . . . . . 25

I. INTRODUCTION ................... 25

II. THE MODEL PRCCESS. . . . . . . . . . . 25

III. THE DYNAMIC MODEL. .............. 26

IV. THE MODEL COMPUTER CODE. . . . . . . . . . 27

v. EXAMPLES .................. 29

REFERENCES. . . . . . . . . . . . . ... 31 


\section{FIGURES}

1 The original Coprecal model process line. . . . . 2

2 The modified Coprecal model process line. . . . . 3

3 Modified Coprecal functional block diagram. . . . . 4

4 Materials accounting strategies for the modified Coprecal process . . . . . . . . . 11

5 Strategy 1, UPAA 2 3, Case 2, 1 day: Cusum and alarm charts............. 17

6 Strategy 1, UPAA 23 , Case 2, 1 week: Cusum and alarm charts............. 18

7 Strategy 1, UPAA 23 , Case 2, 1 month: Cusum and alarm charts.............. 19

8 Strategy 1, UPAA 2 3, Case 2, 1 month: Cusum per formance surfaces. . . . . . . . . . 20

9 Strategy 2, UPAA 21 week, Cusum chart: without vacuum measurement, with distributed vacuum measur ement .................. 20

A-1 MODEL code flow chart ............. 28

A-2 Receipt tank volume and concentration . . . . . 29

A-3 Feed tank volume and concentration. . . . . . . 29

A-4 Precipitator in-process inventory . . . . . . 29

A-5 Calciner in-process inventory . . . . . . . 30

A-6 Calciner primary filter in-process inventory. . . 30

A-7 Calciner reduction container content. . . . . 30

A-8 Calciner primary filter losses: vacuum and final filter............... 30

A-9 Reduction-stabilization primary filter holdup . . 30 A-10 Reduction-stabilization final filter holdup . . . 30

A-11 Screen output: product and scrap ......... 31 


\section{TABLES}

I Coprecal Continuous Flow streams, . . . . . . 4

II Coprecal Batch Transfers. . . . . . . . . . 5

III Measurements for Dynamic Accountability in the

Modified Coprecal Process............ 8

IV Alarm Classification for the Alarm-Sequence Chart - 14

V Detection Sensitivity--Strategy 1, UPAA $23 . . .16$

VI Detection Sensitivity--Strategy 2, UPAA $2 . . . .21$

VII Detection Sensitivity--Strategy 2, UPAA 3.... 21

VIII Detection Sensitivity Comparison--Modified

Coprecal, Original Coprecal, Oxalate (III) . . . . 22

A-I Independent Process Variables in the Model

Coprecal Process. . . . . . . . . . . . 27

A-II Dependent Process Variables in the Model

Coprecal Process (28-day simulation). . . . . . 28 
COPRECAL: MATERIALS ACCOUNTING IN THE MODIFIED PROCESS

by

H. A. Dayem, E. A. Kern, and J. P. Shipley

\begin{abstract}
This report presents the design and evaluation of an advanced materials accounting system for a uranium-plutonium nitrate-to-oxide coconversion facility based on the General Electric Coprecal process as modified by Savannah River Laboratory and Plant and duPont Engineering. The modifications include adding small aliquot tanks to feed the process and reconfiguring the calciner filter systems. Diversion detection sensitivities for the modified Coprecal process are somewhat better than the original Coprecal design, but they are still significantly worse than a same-sized conversion facility based on the oxalate (III) precipitation process.
\end{abstract}

\section{INTRODUCTION}

This study is the third in a series that considers the application of advanced materials accounting techniques to a uranium-plutonium nitrate-to-oxide coconversion facility. 'In the first study, a conceptual design of a materials measurement and accounting system (MMAS) for the preliminary Geperal Electric (GE) Coprecal design $^{2}$ was proposed and evaluated. The study identified several materials accountability problem areas; the most significant of these was the large absolute errors in the inventory measuremients of the nine large feed-blend tanks at the head end of the process. In the second study, ${ }^{3}$ a preliminary assessment of the improvement in materials accountability in a coprecal process that was modified by adding aliquot tanks to feed the process 1 ines ${ }^{4}$ was $g$ iven. since that time, further significant modifications have been made to the original
Coprecal flow sheet. 5 This report discusses the design and evaluation of an advanced MMAS for the modified Coprecal process.

\section{THE REFERENCE COCONVERSION FACILITY}

A. The Major Modifications

Savannah River Plant (SRP), Savannah River Laboratory (SRL), and duPont Engineering have significantly modified the original Coprecal flow sheet. Figures 1 and 2 , respectively, are block diagrams of a single process line of the original and modified processes. The process comprises three parallel lines. These modifications address basic deficiencies in the preliminary design. The most significant modifications are:

- Adding twelve aliquot tanks to feed the coconversion process lines. 


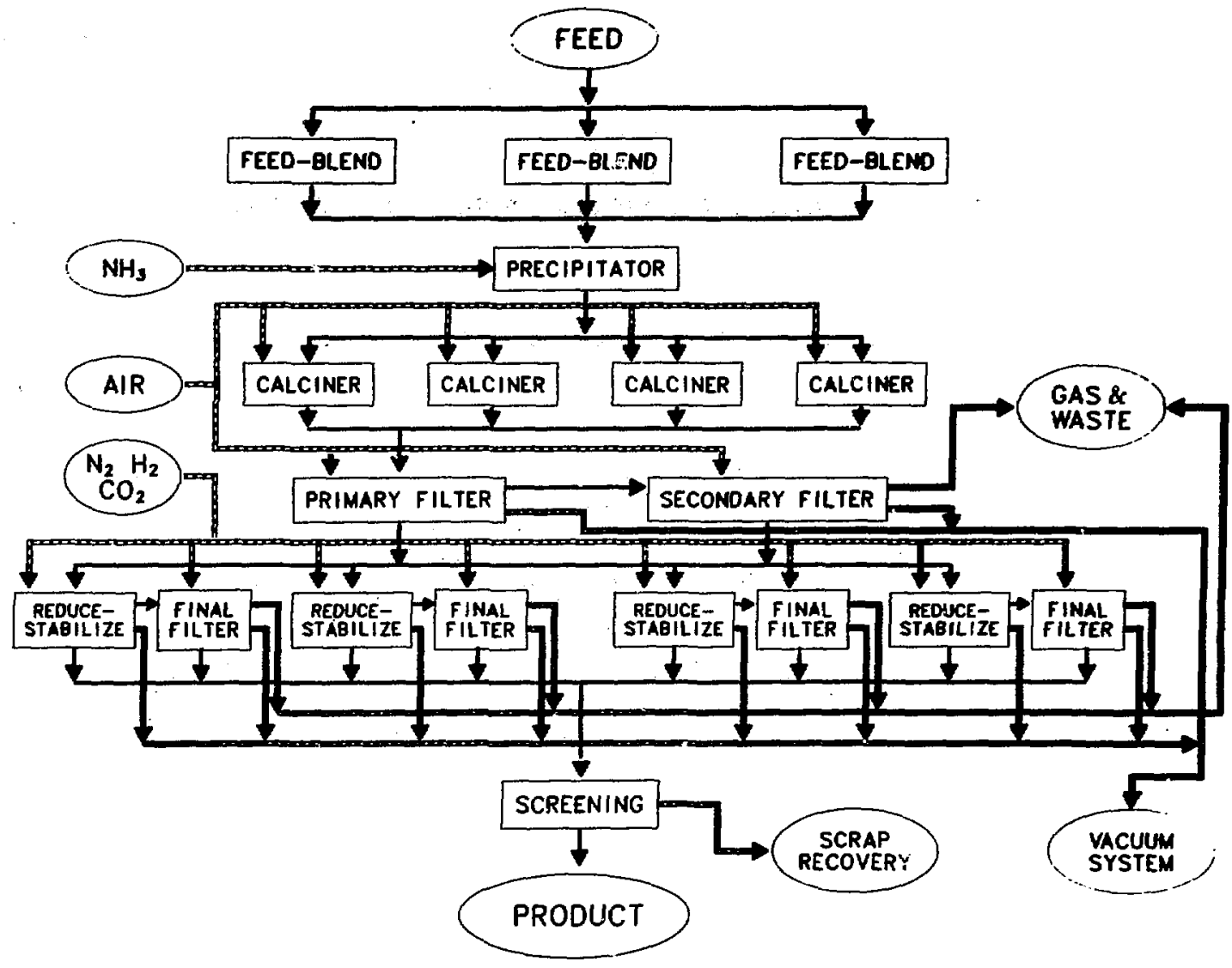

Fig. 1. The original Coprecal model process line.

- Replacing the primary and secondary filters in each process line. In the original design, four calciners are manifolded to a single primary filter and a single secondary filter. In the modified design, a primary and secondary filter was included for each calciner. Each new filter is approximately half the size of the original filter, with 20 sinteced-metal elements per filter instead of 13 .

- Raising the calciner operating temperature from $400^{\circ} \mathrm{C}$ to a range of $500^{\circ}-600^{\circ} \mathrm{C}$.

- Raising the reduction-stabilization operating temperature from a range of $550^{\circ}-650^{\circ} \mathrm{C}$ to as high as $800 \mathrm{C}$.
- Replacing air with nitrogen as the gas used for feed atomizing, jet grinding, bed-fluidizing, and blowing back filters.

- Removing the calciner system offgas coolers.

- Increasing the capacity of the calciner system off-gas scrubbers.

- Increasing the oxide storage capacity from 2-wks to 2-months production.

- Providing for periodic (between daily and weekly) acid flushing of the precipitator.

- Providing for easy replacement of plugged slurry lines and nozzles.

A brief description of the modified Coprecal process is given below. The original flow sheet is described in detail in 


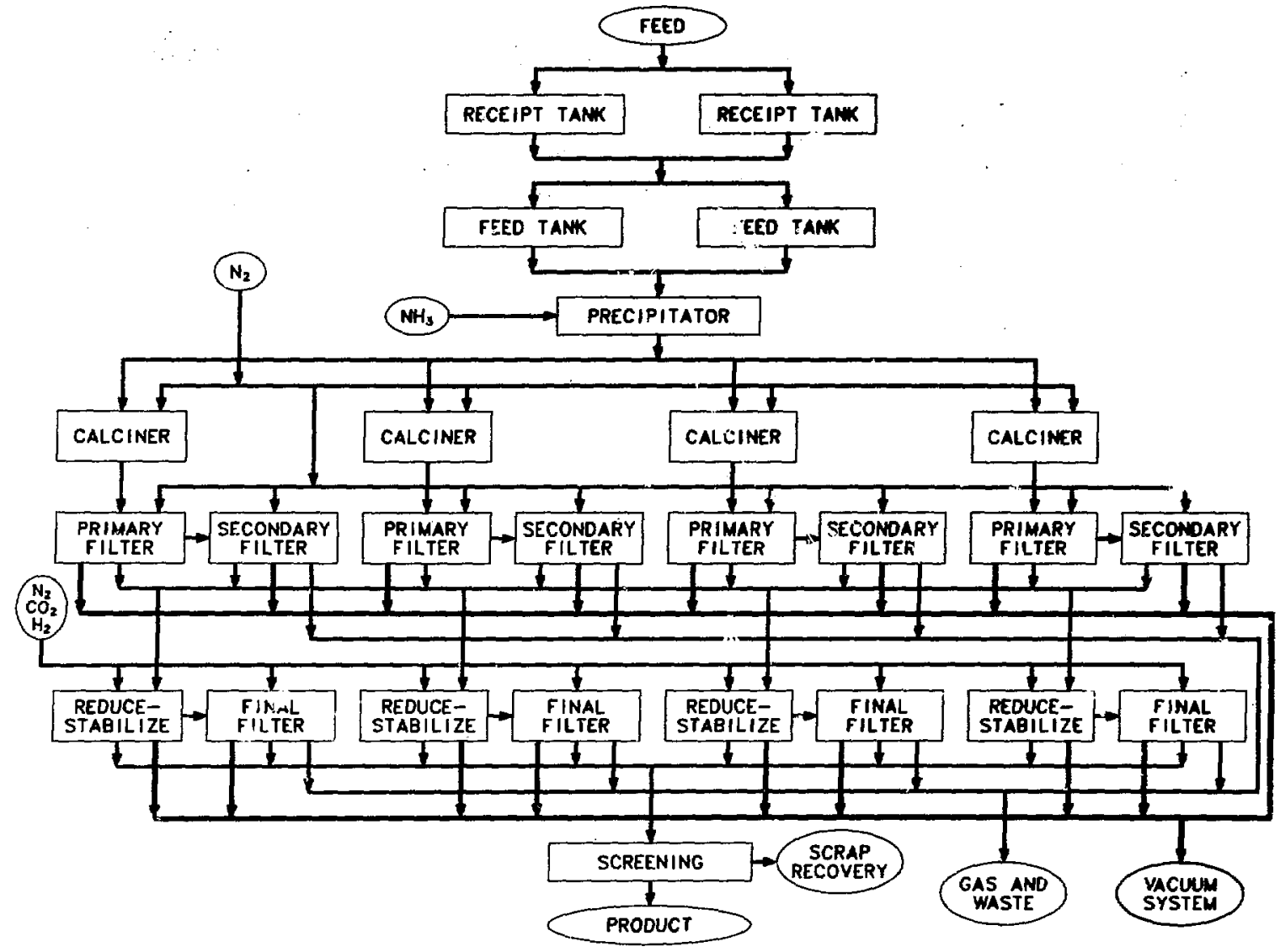

Fig. 2. The modified Coprecal model process line.

Ref. 1, App. A and in Ref. 2, The modified model process used in the computer simulations for this study is described in the Appendi $\mathrm{x}$.

\section{B. The Modified Process}

The reference nitrate-to-oxide cc iversion facility was designed by $G E$ and modified by SRL, SRP, and dupont Engineering for the continuous coprecipitation and calcination of a blended uranium- and plutonium-nitrate solution. 5 The facility was designed to produce $117 \mathrm{~kg}$ of plutonium per day. This amount includes 100 kg of plutonium product from a 10-tonneper-day light water reactor (LWR) fuels reprocessing facility and $17 \mathrm{~kg}$ of plutonium (as a uranium-plutonium-nitrate solution) from scrap recovery. The coprecal process, as demonstrated in laboratoryscale equipment, was extrapolated to production-scale equipment using many process and design assumptions.

Figure 3 is a simplified functional block diagram of the modified process. Table I lists the flow rates for each stream integrated over all three process lines for the continuous portion of the process, and Table II lists the amount of material transferred per batch for the batch portion of the process. Three parallel process lines are required to meet the design-basis throughput in reasonably sized, criticality-safe process equipment. Each line (Fig. 2) comprises two receiptaccountability tanks, two precipitator-feed tanks, a single precipitator, four parallel 


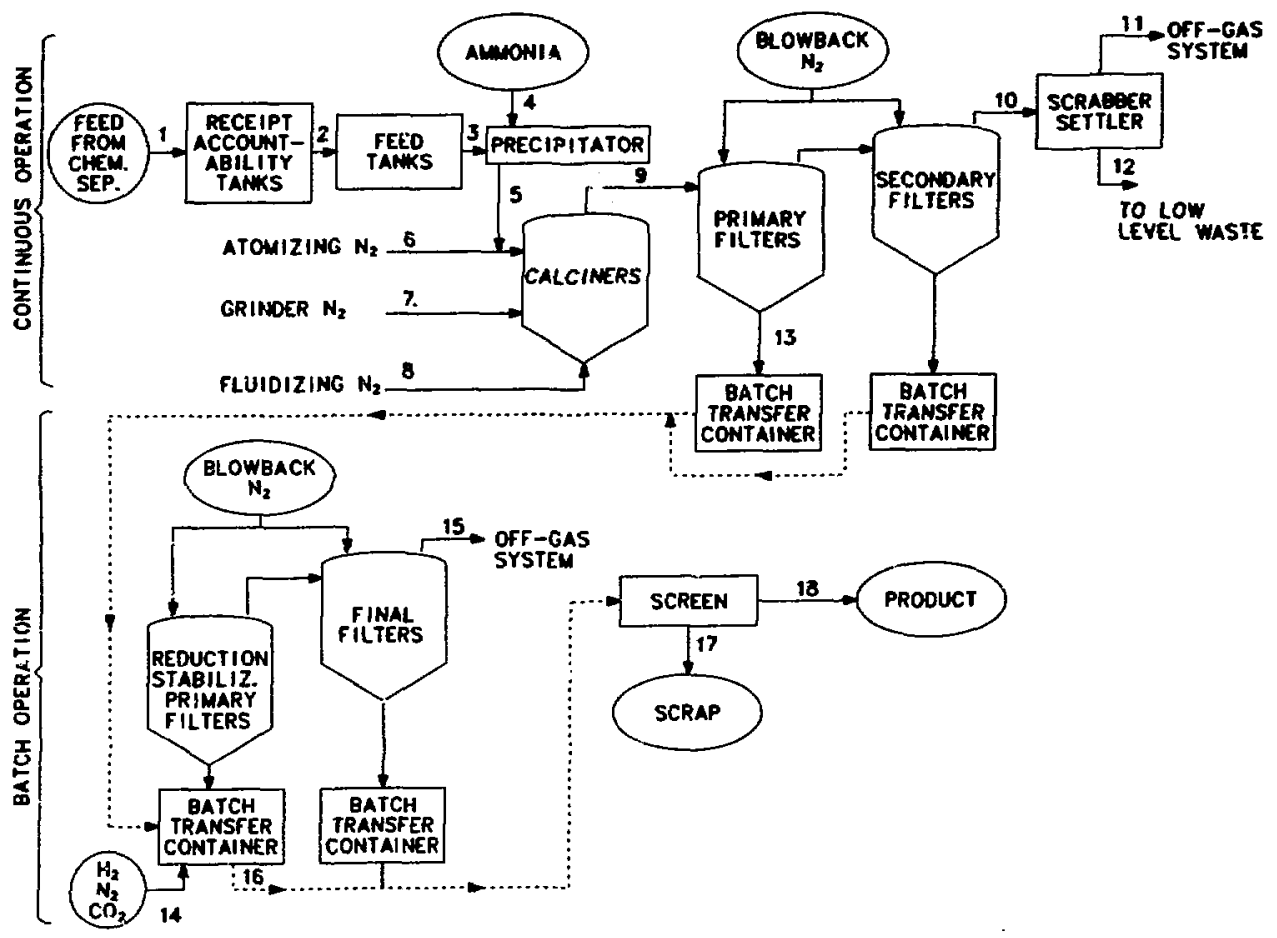

Fig. 3. Modified Coprecal functional block diagram.

TABLE I

COPRECAL CONTINUOUS FLOW STREAMS

\begin{tabular}{|c|c|c|}
\hline Stream No. ${ }^{a}$ & $\begin{array}{c}\text { Total Flow Rateb } \\
(\mathrm{kg} / \mathrm{h}) \\
\end{array}$ & $\begin{array}{c}\text { Plutonium Flow Rateb } \\
(\mathrm{kg} / \mathrm{h})\end{array}$ \\
\hline 1 & 198.9 & 4.86 \\
\hline 2 & 198.9 & 4.86 \\
\hline 3 & 198.9 & 4.86 \\
\hline 4 & 79.3 & -- \\
\hline 5 & 278.2 & 4.86 \\
\hline 6 & 44.8 & - \\
\hline 7 & 97.0 & - \\
\hline 8 & 671.7 & -- \\
\hline 9 & 1091.8 & 4.86 \\
\hline 10 & 1034 . & -- \\
\hline 11 & 891.6 & - \\
\hline 12 & 142.3 & - \\
\hline 13 & 58.2 & 4.86 \\
\hline
\end{tabular}

asee Fig. 3 for stream identification.

bFlow rates may not balance exactly because of roundoff error. 
TABLE. II

\section{COPRECAL BATCH TRANSFERS}

\begin{tabular}{|c|c|c|}
\hline Stream No. a & $\begin{array}{c}\text { Total } \\
\text { kg/batch }\end{array}$ & $\begin{array}{l}\text { Plutoniumb } \\
\mathrm{kg} / \text { batch } \\
\end{array}$ \\
\hline 13 & 38.8 & 3.25 \\
\hline 14 & 236.1 & - \\
\hline 15 & 143.9 & - \\
\hline 16 & 37.0 & 3.25 \\
\hline 17 & 1.9 & 0.26 \\
\hline 18 & 35.1 & 3.09 \\
\hline
\end{tabular}

a See Fig. 3 for stream identification. b A batch is processed every $40 \mathrm{~min}$.

calciner stations (each containing a calciner, a primary filter, and a secondary filter), four parallel reduction-stabilization stations (each containing a primary and a final filter), and a single screening station.

Uranium-plutonium solution is received from the solvent-extraction facility as a nitrate solution containing $\sim 400 \mathrm{~g}$ of heavy metal/L. The uranium-to-plutonium ratio in the solution is nominally 9 to 1 .

Two parallel receipt-accountability tanks and two paralj.el feed tanks are required for each process line to permit continuous operation. Uranium-plutoniumnitrate feed solution from the reprocessing plant is transferred to one of two parallel receipt-accountability tanks. The solution is agitated to assure uniformity, and a sample is taken for analysis. Following certification of the batch, the entire batch is transferred to an empty precipitator feed tank.

One feed tank continuously feeds the precipitator, where ammonium hydroxide is added to produce a slurry of ammonium diuranate and plutonium hydroxide. The precipitator is a cylinder $15 \mathrm{~cm}$ in diameter and $2.5 \mathrm{~m}$ high with a $35-\mathrm{L}$ minimum working volume. A short residence time and high $\mathrm{pH}$ are sufficient in coprecal to produce, a finely divided slurry, in contrast to the usual precipitator goals of promoting crystal growth and producing a filterable material.

The slurry from the precipitator is fed continuously to four parallel fluidized-bed calciner systems to produce mixed uranium-plutonium-oxide powder. Each of the four parallel calciner systems contains a fluidized bed; a primary filter, and a secondary filter. The slurry metered into each bed is calcined to a powder; the powder is eluted from the bed by fluidization and decomposition gases and steam, which carry it to the primary filter.

Each calciner discharges into a separate filter system containing a primary filter and a secondary filter. Each filter contains 20 elements made of porous Inconel metal with a 5- $\mu \mathrm{m}$ rating. Powder collected on a filter is removed by periodically blowing back a few elements at a time. The powder collects in the bcttom of the filter chamber and is discharged approximately every $0.5 \mathrm{~h}$ through a valve to a reduction container. The reduction container is remove $\mathrm{s}$ and sent to a reduction-stabilization station every $8 \mathrm{~h}$. From this point the process line operates in batch mode.

Gas from a calciner primary filter is discharged into a secondary filter similar in construction to the primary filter. The powder content of the entering gas is very low; therefore, the batch-transfer container from the secondary filter is removed only once every operating campaign.

Gas from the calciner secondary filters is discharged to a gas-scrubbing system and then is discharged to a final scrubber. Excess conuiensate is discharged to the low-level waste treatment portion of the reprocessing complex.

A batch-transfer container filled with mixed $\mathrm{UO}_{3}-\mathrm{PuO}_{2}$ powder is transferred from one of four parallel calciner primary 
filters to one of four parallel reductionstabilization stations. Each reductionstabilization station contains a primary and a final filter. These filters are cylindrical chambers $30.5 \mathrm{~cm}$ in diameter and $1.2 \mathrm{~m}$ high. They contain 11 elements similar to those in the calciner filters.

The batch-transfer container is connected to the reduction-stabilization station where gas is passed up through the powder at velocities sufficient to "turn over" the powder. During raduction-stabilization, $\mathrm{UO}_{3}$ is reduced by hot hydrogen gas ( $68 \mathrm{H}_{2}$ in $\mathrm{N}_{2}$ ) to $\mathrm{UO}_{2}$ and is stabilized using hot $\mathrm{CO}_{2}$ to produce powder $\left(\mathrm{UO}_{2.07}\right)$ that does not readily reoxidize in air. The product is then cooled to room temperature by $\mathrm{CO}_{2}$. Almost all the powder entrained in the gas is removed by filters that are blown back periodically. Gas from the primary reduction-stabilization filter is discharged through a final filter to the off-gas treatment system. At the completion of the reduction-stabilization cycle ( $8 \mathrm{hi}$, the batch-transfer container is removed and transferred to the screening station. Unless there is a break in the primary filter, the reduction-stabilization final filter is cieaned only at each physical inventory.

At the screening station, the stabilized powder is removed from the batchtransfer container and passed to a screen system to remove any foreign particles and oxide agglomerates exceeding $0.15 \mathrm{~mm}$ in diameter. The powder passing through the screen is collected in a tared storage can. When all powder from a transfer container has been screened, material on the screen is dumped into a scrap container, which is sent to scrap recovery when full. The product storage can is removed, sampled, weighed, sealed, and transferred to a storage vault.

\section{MATERIALS MEASUREAETT AND ACCOUNTIIN SYSTEX}

Three wajor functions of the whs ar:

- Data collection (inciuding measurements).

- Data analysis (for diversion detection), and

- Data dissemination or reporting.

As currently performed by conventional inventory control methods, these functions rely heavily on materials balance accounting following periodic shutdown, cleanout, and physical inventory. The classical materials balance associated with this system is drav.n around the entire plant or a major portion of the process. The balance is formed by adding all measured receipts to the initial measured inventory and suberacting from that sum all measured removals and the final measured inventory. During routine production, materials control is vested largely in administrative and process controls, aughented by secure storage for discrete iteans.

Conventional materialo balance accounting is essential to safeguards control of nuclear material; however, it has inherent limitations in sensitivity and timeliness. Sensitivity is limited by measurement uncertainties that can mask losses of nuclear materials. In large plants, these losses, although small compared to plant throughput, may be significant. Timeliness is limited by the frequency of physical inventories. There are practical limits to how often a facility can shut down its process and still be productive. on the other hand, periodic physical inventories including process shutdown and cleanout are necessary to establish reference points for a dynamic accounting system. In the Coprecal process, frequent cleanouts may be necessary because process designers 
expect some line plugging and material accumulation. The frequency of these cleanouts is not known because the process has not been built. Therefore, no attenpt was made to include these shutdowns and cleanouts in the materials accounting strategies.

The reference mas conbines conventional and dynamic materials accounting 7,8 techniques. It incorporates recently developed nondestructive assay (NDA) technology, state-of-the-art conventional measurement methods, special in-plant sensors, plant instrumentation signals, and effective statistical techniques for data an:? sis supported by computer and data-basemanagement technology. Conventional materials balance area (MBA) accounting methods are augmented by unit process accounting, where the MBAs are partitioned into discrete accounting envelopes called unit process accounting areas (UFAAs). A unit process is one or more chemical or physical processes chosen on the basis of process logic and a consideration of whether materials balances can be drawn frequently around it during process operation. When an MBA is divided into UPAAs and all significant materials flows and in-process inventories are measured, quantities of material much smaller than the total plant inventory can be controlled. Discrepancies are localized to that portion of the process contained in the UPAA.

Materials balances drawn around UPAAs during plant operation are called dynamic materials balances to distinguish them from balances drawn after a cleanout and physical inventory. Ideally, all dynamic materials balances would be zero unless nuclear material had been diverted. In practice, they are never zero. First, measured values are inexact because of the errors inherent in any measurement. Second, constraints on cost or effects on materials processing operations may dictate that not all components of a materials balance be measured equally often; therefore, even if measurements were exact, the dynamic materials balances would not be zero until closed by additional measurements. In the interia, historical data wight be used to estimate unmeasured material, and the estimates could be updated when additional measurements becane available.

Adjacent UPAAs can be combined to form larger UPAAs by eliminating the intervening transfer measurements. Such combinations of overlapping UPAAs are useful for cross checking and for system redundancy that allows continued materials accounting if analyses fail or samples are not available.

Unit process accounting must be used flexibly throughout the facility. Its application should be graded according to the safeguards strategic value and vulnerability of the material; hence, the concept of graded safeguards. For example, in the coconversion facility, uranium-plutoniumoxide powder at the product loadout area would be somewhat more desirable to a potential divertor than the relatively dilute ( $v 40 \mathrm{~g}$ plutonium/L, $2400 \mathrm{~g}$ heavy metal $/ L$ ) uranium-plutoniun-nitrate solution in the feed-blend tanks, and both would be more desirable than the slurry ( $25 \mathrm{~g}$ plutonium $/ L$ ) inside the precipitators. To escape detection by the MMAs, a divertor would have to remove small amounts of marerial over a long period, possibly from several process locations, thereby increasing his risk of detection by the other elements of the safeguards system.

\section{A. Measurements}

Measurements of liquids, solids, and slurries are reguired for application of dynamic accounting to the modified coprecal process. Table III lists proposed key measurement points, measurement techniques, and their estimated uncertainties for dynamic materials accounting in the main coconversion process. Except for inventory measurements of the feed-accountability 
TABLE III

MEASUREMENTS FOR DYNAMIC ACCOUNTABILITY IN THE MODIFIED COPRECAL PROCESS

\begin{tabular}{|c|c|c|c|c|c|c|c|}
\hline Measuzement Point & $\begin{array}{l}\text { Number of } \\
\text { Measurement } \\
\text { Points } \\
\end{array}$ & $\begin{array}{c}\text { Material } \\
\text { Description }\end{array}$ & Measurement Type & $\begin{array}{c}\text { Instrument } \\
\text { Precision } \\
8(1 \sigma) \\
\end{array}$ & $\begin{array}{c}\text { Calibration } \\
\text { Error } \\
8(1 \sigma) \\
\end{array}$ & $\begin{array}{r}\text { Calibr } \\
\text { Peri }\end{array}$ & $\begin{array}{l}\text { ation } \\
\text { od }\end{array}$ \\
\hline $\begin{array}{l}\text { Receipt-account- } \\
\text { ability inventory }\end{array}$ & 6 & $\begin{array}{l}\mathrm{U}-\mathrm{Pu} \text { in } \mathrm{HNO}_{3} \\
400 \mathrm{~g} \mathrm{HM} / \mathrm{L} \\
10 \% \mathrm{Pu}\end{array}$ & $\begin{array}{l}\text { Volume } \\
\text { Concentration } \\
\text { (chom. anal.) }\end{array}$ & $\begin{array}{l}0.2 \\
0.2\end{array}$ & $\begin{array}{l}0.1 \\
0.1\end{array}$ & $\begin{array}{l}\text { Physical } \\
\text { Day }\end{array}$ & inventory \\
\hline $\begin{array}{l}\text { Precipitator feed } \\
\text { tank inventory }\end{array}$ & 6 & $\begin{array}{l}\mathrm{U}-\mathrm{Pu} \text { in } \mathrm{HNO}_{3} \\
400 \mathrm{~g} \mathrm{HM} / \mathrm{L} \\
108 \mathrm{Pu}\end{array}$ & $\begin{array}{l}\text { Volume } \\
\text { Concentration } \\
\text { (abs -edge } \\
\text { densi.tometry) }\end{array}$ & $\begin{array}{l}0.2 \\
0.5\end{array}$ & $\begin{array}{l}0.1 \\
0.3\end{array}$ & $\begin{array}{l}\text { Physical } \\
\text { Day }\end{array}$ & inventory \\
\hline $\begin{array}{l}\text { Precipitator } \\
\text { inventory }\end{array}$ & 3 & slurry & NDA, neutron & 10 & -- & Physical & inventory \\
\hline Calciner inventory & 12 & $\begin{array}{l}\mathrm{PuO}_{2}, \mathrm{UO}_{3} \\
0.9 \mathrm{~kg} \mathrm{Pu}\end{array}$ & NDA, neutron & 10 & --- & Physical & inventory \\
\hline $\begin{array}{l}\text { Primary filter } \\
\text { holdup }\end{array}$ & 12 & $\begin{array}{l}\mathrm{PuO}_{2}, \mathrm{UO}_{3} \\
0.75 \mathrm{~kg} \mathrm{Pu}\end{array}$ & NDA, neutron & 10 & --- & Physical & inventory \\
\hline $\begin{array}{l}\text { Secondary filter } \\
\text { holdup }\end{array}$ & 12 & $\begin{array}{l}\mathrm{PuO}_{2}, \mathrm{UO}_{3} \\
0.75 \mathrm{~kg} \mathrm{Pu}\end{array}$ & NDA, neutron & 10 & -- & Physical & inventory \\
\hline $\begin{array}{l}\text { Reduction container } \\
\text { level }\end{array}$ & 12 & $\begin{array}{l}\mathrm{PuO}_{2}, \mathrm{UO}_{3} \\
0-90 \mathrm{~cm}\end{array}$ & $\begin{array}{l}\text { Level } \\
\text { Density }\end{array}$ & 10 & 0.1 & Physical & inventory \\
\hline $\begin{array}{l}\text { Reduction container } \\
\text { contents }\end{array}$ & 3 & $\begin{array}{l}\mathrm{PuO}_{2}, \mathrm{UO}_{3} \\
3.3 \mathrm{~kg} \mathrm{Pu}\end{array}$ & NDA, neutron & 2 & 1 & Day & \\
\hline $\begin{array}{l}\text { Reduction-stabili- } \\
\text { zation holdup }\end{array}$ & 12 & $\begin{array}{l}\mathrm{PuO}_{2}, \mathrm{UO}_{2} \\
0.2 \mathrm{~kg} \mathrm{PUU}\end{array}$ & NDA, neutron & 10 & $-\infty$ & Physical & inventory \\
\hline Final filter holdup & 12 & $\begin{array}{l}\mathrm{PuO}_{2}, \mathrm{UO}_{2} \\
0.2 \mathrm{~kg} \mathrm{Pu}\end{array}$ & IDA, neutron & 10 & -- & Physical & inventory \\
\hline Scrap & 3 & $\mathrm{PuO}_{2}, \mathrm{UO}_{2}$ & NDA, neutron & 2 & 5 & Day & \\
\hline Vacuum & 3 & $\mathrm{PuO}_{2}, \mathrm{UO}_{2}$ & NDA, neutron & 2 & 5 & Day & \\
\hline Product & 3 & $\begin{array}{l}\mathrm{PuO}_{2}, \mathrm{UO}_{2} \\
3.2 \mathrm{~kg} \mathrm{Pu} \\
37 \mathrm{~kg} \mathrm{HM}\end{array}$ & $\begin{array}{l}\text { NDA, neutron } \\
\text { or calorimet:er }\end{array}$ & 1 & 0.5 & Day & \\
\hline
\end{tabular}


tanks, all requisite measurements are based on NDA techniques.

Estimates of measurement errors have been grouped in two categories. Instrument precision represents the estimated scatter in a set of individual raw measurements (for example, the uncertainty caused by counting statistics in NDA measurements). Calibration error represents the uncertainty in converting raw, measured values to the quantity of interest, for example, converting raw counts to plutonium mass for NDA measurements. Calibration errors are the most difficult to estimate because they include uncertainties in standards, calibration parameters, instrument environment, and measurement controls. He assume that appropriate standardization techniques will be available. No calibration errors are quoted for precipitator, calciner, or filter inventory measurements or for holdup measurements because these errors approximately cancel in the error models for materials balances and cumulative summations of materials balances (Cusums).

inventory measurements in the receiptaccountability tanks combine a volume measurement with a concentration measurement. There is some question as to whether a mass measurement is more appropriate than a volume measurement. Mass measurement is usually of better quality than volume measurement, but this has not been demonstrated on procsss tanks. Therefore, volume measurements are used in this analysis. uranium and plutonium concentrations are measured by analytical chemistry. Appropriate analytical methods for determining isotopic and total element composition are given in Ref. 1, App. D.

Precipitator feed tank inventory is determined by combining volume and concentration measurements. The coricentration is measured by absorption-edge densitometry, an element-specific NDA nethod that can be applied on-line or at-line in most areas amenable to gross absorption measurements. With proper choice of cell path length and either $\mathrm{K}$ - or $\mathrm{L}_{\text {III-absorption }}$ edges, plutonium concentrations between us and $400 \mathrm{~g} / \mathrm{L}$ can be measured to a precision of better than $1 *(1 \sigma)$ in the presence of impurities. Furthermore, the technique is well suited to simultaneous measurement of plutonium and uranium in a coprocessing mode, and such measurements have been demonstrated in the laboratory. 6

In practice, reliable measurements of calciner in-process inventory may be alfficult for three reasons:

- The calciners operate at high temperatures and neutron detectors -will have to operate reliably in a relatively high-temperature environment.

- The proximity of the calciners may introduce interferences among the neutron counters.

- The crowded environment of the instruments will complicate instrument calibration and maintenance procedures.

Accurate measurements of inventory and holdup in the precipitators and filters also are difficult because of material form and equipment geometry. The methods chosen require that chemical and isotopic compositions be available by analysis of samples taken from the process.

Inventory measurement in a reduction container attached to a calciner primary filter combine a level measurement with a density factor. The level measurement can be made lising commercially available ultrasonic, laser, or $\gamma-r a y$ devices. The density factor is based on historical data. Inventory measurement in a reduction container attached to a reduction-stabilization filter is based on a measurement of the container contents before the container is attached to the filter. This is possible because the container contents are essentially static during processing.

In general, each NDA instrument nust be designed for its apecific application. Eguipment design and operating features 
must be consldered in terms of background, shielding, multiplication factors, and accessibility for measur ment, maintenance, and calibration. Specific instrument systems must be evaluated for reliability, sensitivity, and operational acceptability under field conditions. The measurement system, whether for conventional or dynamic materials accounting, requires that appropriate standardization techniques be available and that an effective measurement control program be in force.

The following conclusions can be drawn from a comparison of the measurements required for the original design (see Ref. 1, Sec. III) with the measurements required for the modified design.

- Adding aliquot tanks improves the measurement system because measurement errors on small tanis are smaller than errors on large tanks.

- Adding aliquot tanks to feed the precipitator precludes the need for flow measurements of the precipitator feed streams.

- Adding independent filters to each calciner requires an additional neutron counter for each filter.

- Adding independent filters to each calciner changes the materials accounting logic, requiring the addition of reduction-container level measurements.

- Adding independent filters to each calciner may increase neutron "cross-talk" between vessels within the calciner syetem, thus degrading measurement quality.

- Increasing operating temperatures in the calciner and the reductionstabilization stations may make holdup measurements in these vessels more difficult because instruments will have to operate at higher temperatures or be placed further from the measurement source.
B. Dynamic Materials Accounting Strategies

The coconversion process is amenable to several dynanic accounting strategies because it comprises parallel process lines and because the material being processed is relatively pure. Parallel process lines can be easily treated as separate UPARs. Processing relatively pure material facilitates the use of near-real-time meanurements, thus presenting more possibilities in partitioning each process line. As shown in Fig. 4, the accounting strategies can be developed hierarchically:

1) Treat the entire process area as a single UPAA (UPAA 123 );

2) Treat the receipt-accountability tanks as a single UPAA (UPAA 1), and divide the rest of the process into three parallel UPAAs, one for each process line (UPAA $23 \mathrm{~A}$, UPAA $23 \mathrm{~B}$, and UPAA $23 \mathrm{c}$ );

3) Divide each process line into two UPAAs in series, precipitation/ calcination (UPAA $2 \mathrm{~A}, 2 \mathrm{~B}$, and $2 \mathrm{C})$ and reduction-stabilization/ screening (UPAA $3 \mathrm{~A}, 3 \mathrm{~B}$, and 3 c).

In each accounting strategy, dynamic materials balances are formed from periodic measurements (Sec. III.A) of transfers and in-process inventories.

Two strategies for dynamic materials accounting in the modified Coprecal process were investigated for this study. In both strategies, Unit Process Accounting Area 1 (UPAA 1) consists of the six receiptaccountability tanks and is common to all three parallel process lines. Dynamic materials accountability in UPAA 1 was treated in Ref. 3.

As shown in Fig. 4, the three process lines from the precipitator feed tanks to the product load-out canisters are separate and independent from each other. Therefore, in accounting strategy 1 , dynamic materials accounting is applied separately 


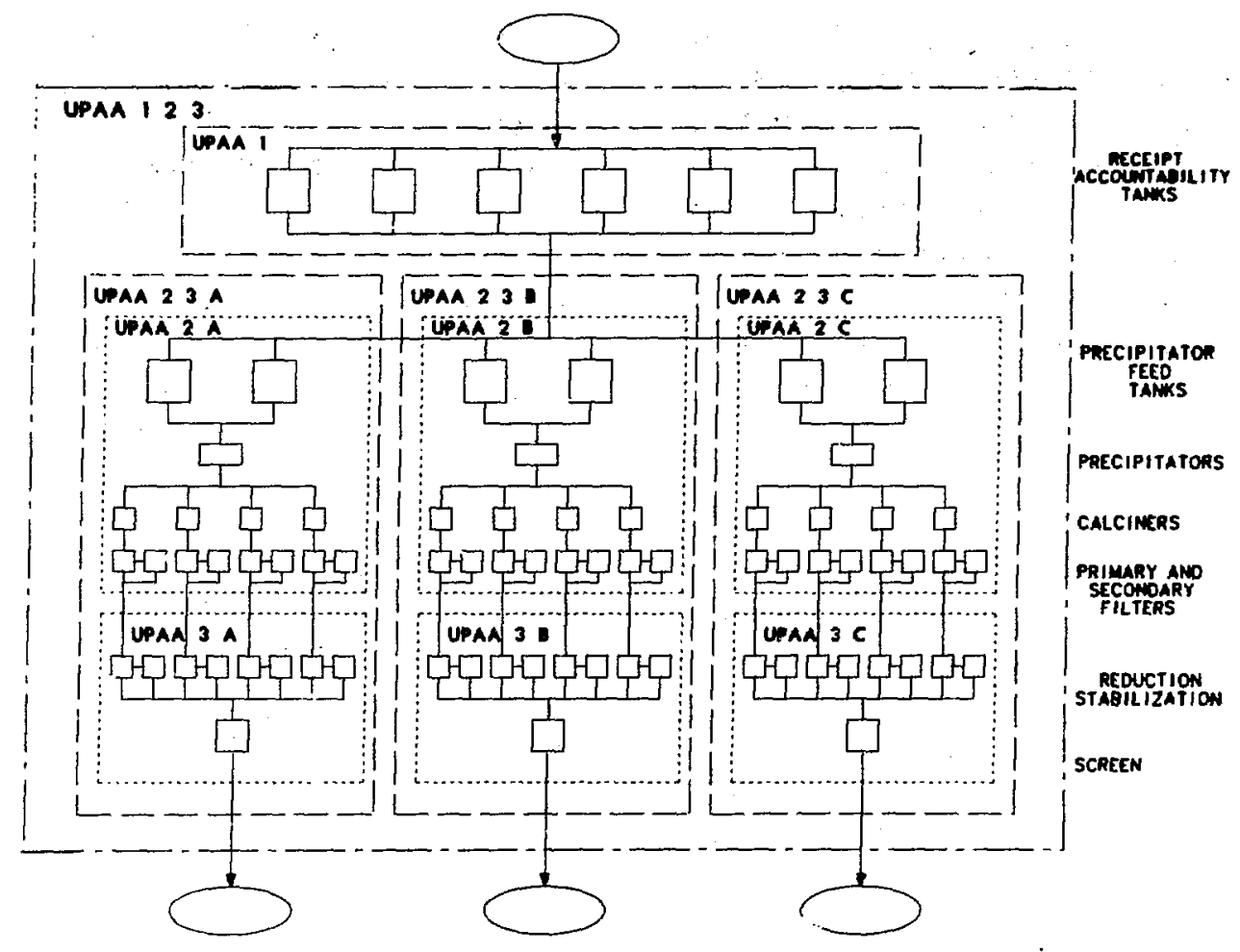

Fig. 4. Materials accounting strategies for the modified Coprecal process.

to each process line starting with the precipitator feed tanks. In accounting Strategy 2, each process line is divided into two UPAAs.

1. Strategy 1 - UPAA $23 A_{1} 23 B_{\text {, }}$ and $23 \mathrm{C}$. In accounting strategy 1 , each process line is treated as a single UPAA. A dynamic materials balance is obtained every $4 \mathrm{~h}$ by combining measurements of the feed, product, and scrap batches with measurements of the process line in-process inventory. One batch is fed to a precipitator and two product batches are produced every $4 \mathrm{~h}$. The volume and concentration of each batch is measured before the batch is fed to the precipitator. Each precipitator feed tank, in turn, feeds its associated precipitator until the tank is empty; then feed is drawn from the full feed tank. The in-process inventory for each process line is determined every $4 \mathrm{~h}$ by combining in-process inventory measurements of (1) the precipitator, (2) the four calciners, (3) the four primary filters, (4) the four secondary filters, (5) the four reduction-stabilization filters, (6) the four final filters, and (7) eight reduction-stabilization containers (four are connected to the primary filters and four are connected to the reduction-stabilization filters). The in-process inventory in the vacuum systein canister is measured once each day and is used to update the materials accounting data base leach prncess line is assumed to have its own vacuum system).

2. Strategy 2. If the measured contents of the reduction-stabilization container as it is transferred from a calciner primary filter to a reduction-stabilizstion station are used as a transfer measurement, then each process line can be treated as two UPAAs in series. 
a. UPAA 2 A, 2 B, 2 c. Each UPAA comprises two precipitator feed tanks, a precipitator, four calciners, four primary filters, and four secondary filters, A dynamic materials balance is taken ever $x$ $4 \mathrm{~h}$ by combining measurements of one feed batch and two product batches (the filled reduction-stabilization containers) with the appropriate in-process inventory measurements.

b. UPAA 3 A, 3 B, 3 C. Each UPAA comprises four parallel reduction-stabilization stations and a screening station. Materials balances can be drawn around each batch because batch integrity is maintained in this UPAA. The batch residence time is 8 h. A materials balance is obtained by combining the initial and final in-process inventory in the roruction-stabilization filters that processed the batch with measuremerts of the batch iefore and after processing and measurements of the scrap generated in screening the batch.

\section{MODELING, SIMULATION, AND ANALYSIS} TECHNIQUES

A. Modeling and Simulation Approach

Modeling anc simulation techniques were used to design and evaluate the MMAS because the coprecal process has not been used or tested in an industrial-scale facility. Modeling and simulation techniques permit prediction of the behavior of materials flows over a wide range of operating parameters and allow the rapid accumulation of data equivalent to relatively long operating periods. Alternative operating, measurement, and accounting strategies can be readily compared. Even if nuclear fuel-cycle facilities with advanced Moss were operating, their use for the design and evaluation of alternative strategies probably would be too timeconsuning, expensive, and impractical.
The modeling and simulation approach has been used extensively in safeguards concept studies.1,9-13 This approach requires $^{14}$ (1) a detailed dynamic model of the process based on actual design data and operator experience; (2) simulation of the model process on a digital computer; (3) a dynamic model of each measurement system based on best estimates of instrument performance and behavior; (4) simulation of accountability measurements applied to nuclear materials flow and in-process inventory data generated by the model process simulation: and (5) evaluation of simulated materials balance data from various materials accounting strategies. Brief descriptions of the process and measurement models are given below. A detailed description of the process model is given in the Appendix.

1. Process Model. A computer code, MODEL, based on standard Honte Carlo techniques, 15,16 was written to simulate the operation of the process. The GASP $\mathrm{IV}^{17}$ simulation package is used to schedule events. When an event is scheduled in a particular process step, the values of all concentrations, materials transfers, and in-process inventory associated with that step are computed and stored in a data matrix. The MODEL computer code is described in the Appendix.

2. Measurement Models. Measurement medels are applied to the simulated process-flow and in-process inventory data by using the Nonte Carlo computer code MEASIM (measurement simulation) developed for that purpose. MEASIM simulates instrument operation by using either an additive or a multiplicative measurement-error model (Ref. 1, Sec. IV), then stores the measured values, or appropriate combinations thereof, with their uncertainties, in a measurement data base for eventual retrieval and 
analysis by the safeguards data-analysis code DECANAL (DECision ANALysis).

3. Materials Balances. The measured values computed in MEASIM are combined to form dynamic materials balances. A mate$r$ ials balance is a linear combination of measured transfers (inputs positive, outputs negative) and measured inventories (initial inventory positive, final inventory negative). The dynamic materials balance frequency is dictated by process logic, for example, by the feed and product batch frequency.

\section{B. Data Analysis Techniques}

The effectiveness of proposed dynamic accounting strategies is evaluated by applying decisicn-analysis techniques to the simulated accounting data. Analysis of materials accounting ciata for detection of possible nuclear materials diversion is one of the major functions of the MMAs. Diversion may occur in the range between two basic patterns: abrupt diversion (the single theft of a relatively large amount of nuclear material) and protracted diversion (repeated thefts of nuclear material on a scale too small to be detected in a single materials balance because of measurement uncertainties).

The use of unit process accounting and dynamic materials balances enhances the ability to detect such diversions, but this use also inundates the operator of the safeguards system with materials accounting data. Furthermore, although these data contain much potentially useful information concerning both safeguards and process control, the significance of any isolated (set of) measurements is seldom readily apparent. Thus, the safeguards system operator could be presented with an overwhelmingly complex body of information from which he must repeatedly determine the status of the materials accounting system for the plant. Clearly, he must be assisted by a coherent, logical framework of tools that address these problems.

Decision analysis, 18-21 which combines techniques from estimation theory. decision theory, and systems analysis, is such a framework and is well suited for statistical treatment of the dynamic materials accounting data that become avaliable sequentially. Its primary goals are (1) detection of the event(s) in which nuclear material has been diverted, (2) estimation of the amount(s) diverted, and (3) determination of the significance of the estimates.

The detection and estimation functions of decision analysis are based on classical hypothesis testing and modern state-variable estimation techniques. The systems analysis portion attempts to set thresholds for the hypothesis tests in a rational fashion, for example, by using utility theory to determine desirable false-alarm and detection probabilities.

The detection function. is based on acceptance of the hypothesis that some (initially unknown) amount of nuclear material is missing versus the hypothesis that all nuclear material is present. One useful kind of decision test compares a likelihood ratio to a threshold, the likelihood ratio being defined roughly as the ratio of the probability that nuclear material is missing to the probability that it is not, with the threshold determined by the desired false-alarm and detection probabilities. This structure can accommodate parametric tests, which require detailed knowledge of measurement-error statistics, and nonparametric tests, which do not. Furthermore, the set of tests enables a search for diversion that may have occurred in any pattern, and in each test all possible sequences of the available materials balance data are siamined.

The decision analysis algorithms include the Shewhart chart, Cusum test, uniform diversion test (UDT), sequential 
variance test (SVT), Bmoothed materials balance test (SMBT), and wilcoxon rank sum test. The algorithms for the shewhart chart, Cusum, UDT, SVT, and SMBT are structured to account for correlated data so that correct variances are computed for the associated decision tests. The actual false-alarm and detection probabilities for the wilcoxon test depend on the degree of data correlation. If correlations are large, the wilcoxon test performance will suffer unless corrective measures are taken.

C. Data Analysis Graphic Aids--Alarm Charis

The decision tests must examine ail possible sequences of the available materials balance data because, in practice, the time at which a sequence of diversions begins is never known beforehand. Furthernore, to ensure uniform application and interpretation, each test should be performed at several levels of significance (false-alarm probability). Thus, it is essential to have a graphic display that indicates those sequences that cause alarms, specifying each by its length, time of occurrence, and significance. One such tool is the alarm-sequence chart, 9 which has proven useful in summarizing the results of the various tests and for identifying trends.

To generate the alarm-sequence chart, each sequence that causes an alarm is assigned a descriptor that classifies the alarm according to its significance and a pair of integers $\left(r_{1}, r_{2}\right)$ that are, respecively, the indexes of the initial and final materials balances in the sequence. The alarm-sequence, chart is a point plot of $r_{1}$ vs $r_{2}$. for each sequence that caused an alarm, with the significance range of each point indicated by the plotting symbol. The correspondence of plotting symbol to significance is given in Table IV. The symbol. T denotes seguences of such low
TABLE IV

\section{ALARM CLASSIFICATION FOR THE} ALARM-SEQUENCE CHART

Classification (Plotting Symbol)

False-Alarm Probability

$$
\begin{array}{cc}
\text { A } & 10^{-2} \text { to } 5 \times 10^{-3} \\
\text { B } & 5 \times 10^{-3} \text { to } 10^{-3} \\
\text { C } & 10^{-3} \text { to } 5 \times 10^{-4} \\
\text { D } & 5 \times 10^{-4} \text { to } 10^{-4} \\
\text { E } & 10^{-4} \text { to } 10^{-5} \\
\text { F } & <10^{-5} \\
\text { T } & >0.5
\end{array}
$$

significance that it would be fruitless to examine extensions of them; the position of the symbol $T$ on the chart indicates the termination point.

For example, consider a sequence of materials balance data beginning at balance number 12, and suppose that one of the tests gives an alarm with a false-alarm probability of $2 \times 10^{-4}$ at balance number 19. Then on the alarm-sequence chart for that test, the letter $D$ would appear at the point $(19,12)$. This procedure continues for all possible sequences of the available materials balances. It is always true that $r_{1} \leq r_{2}$, so that all symbols lie to the right of the line $r_{1}=r_{2}$ through the origin. Persistent data trends (repeated diversions) cause long alarm sequences $\left(r_{1} \ll r_{2}\right)$, and the associated symbols on the alarm chart extend far to the right of the 1 ine $r_{1}=r_{2}$.

\section{Systems Performance Analysis}

Essential to the design of nuclear materials accounting systems is an analysis of their expected performance in detecting losses of nuclear material. 22 systems performance analysis, in turn, implies the definition of suitable performance measures that can be easily related to established 
criteria. Thus, there are two aspects of the analysis problem:

(1) defining per-

formance measures and (2) relating those measures to established, quantitative performance criteria.

Performance measures for any nuclear materials accounting system embody the concepts of loss-detection sensitivity and loss-detection time. Because of the statistical nature of materials accounting, loss-detection sensitivity can be described in terms of the probability of detecting some amount of loss while accepting some probability of a false alarm. Loss-detection time is the time required by the accounting system to reach some specified level of loss-detection sensitivity. Note that the loss scenario is not specified; that is, whether the loss is abrupt or protracted, the total loss is the measure of performance. Note also that loss-detection time refers only to the internal response time of the accounting system.

The performance of any accounting system is describable by some function

$$
P[I, N, \alpha],
$$

where $P$ is the accounting system's probability of loss detection, $L$ is the total loss over a period of $\mathrm{N}$ balances, and $\alpha$ is the false-alarm probability. Thus, a convenient way of displaying system performance would be a three-dimensional graph of the surface $P$ versus $L$ and $N$ for some specified value of $\alpha$. We call such graphic displays performance surfaces. They are plotted in the three-dimensional space (N, I, P). They portray the expected performance of an accounting system as a function of the three performance measures, loss, time, and detection probability, rather than as a single point.

Because systems performance may depend on the details of a particular diversion strategy as well as on details of the accounting system, the overall performaxe may be difficult to quartify. Portunately, however, the Cusum test does not depend on how the material was lost, but responds only to the total loss $L$ during any tims interval $N$. Moreover, the Cusum test detects any loss relatively well, even though it is seldom the best test for any particular scenario. $18,23,24$

If the cusum test is always among the tests applied to the accounting data, the performance of the accounting system will be as good as the loss-detection power of the Cusum test, regardless of loss scenario. Thus, the cusum test provides a conservativu, scenario-independent measure of systems performance.

Performance surfaces generated by the Cusum test are referred to as Cusum performance surfaces because they are approximations to the expected system's performance. The performance of the more powerful tests for specific loss scenarios should always be compared with the cusum test performance to ensure that the cusum approximation is not unduly pessimistic.

\section{EFFECTIVENESS EVALUATION}

The ability of the dynamic materials accounting system to detect diversion of plutonium from the modified coprecal process has been estimated for two accounting strategies. In strategy 1 , each process line, from the precipitator feed tanks to the screening station, is treated as a single UPAA--UPAA $23 \mathrm{~A}, 23 \mathrm{~B}, 23 \mathrm{C}$. In strategy 2, each process line is treated as two UPAAs in series; the first UPAA (UPAA 2) includes the precipitation and calcination processes, and the second UPAA (UPAA 3) includes the reduction/stabilization and screening processes. 
A. Strategy 1--UPAA 23

Dynanic materials accounting detection sensitivities for periods from $4 \mathrm{~h}$ ( 1 balance) to 1 month (168 balances) are given in Table $v$. The materials balance frequency is governed by the feed and product batch frequencies. A feed batch is transferred to the precipitator every $4 \mathrm{~h}$, and a product batch is transferred to the vault every $2 \mathrm{~h}$. Therefore, a materials balance is taken every $4 \mathrm{~h}$ when a precipitator feed tank is empty.

Two cases are considered in Table $v$. In Case 1, no instruments are recalibrateó within the accounting period. In Case 2, the input concentration measuring instruments and the output NDA instruments are recalibrated daily (Table III).

The detection sensitivities in Table $v$, and all other tables for the dynamic materials accounting system, are given at the 3- $\sigma$ limit. The sensitivities are based on the cusum test because it gives a conservative estimate that is indepsndent of diversion scenario. Monte Carlo simulation of the process and the measurements yielded a detection probability $>508$ with a falsealarm provability of <lo. An example of the simulation results is given in Figs. 5-7.

The detection sensitivity for a single materials balance is dominated by the uncertainty in measuring the in-process inventory. The in-prccess inventory measurement error and the transfer measurement errors are approximately equal after 10 balances for Case 1 and after 14 balances for Case 2. Note that in Case 2 daily calibration of the input concentration and the output transfer measuring instruments results in a lower propagated transfer error. Detection sensitivities for periods of 1 wk or more are dominated by uncertainties in the transfer measurements.

The difference in detection sensitivities due to calibration is illustrated in Table $\mathbf{V}$ and Fig. 8. For a l-month accounting pericd, the detection sensitivity is improved by more than a factor of three if the input concentration measuring instruments and the output measuring instruments are calibrated daily. Concroiling these correlated errors that dominate the materials balance uncertainty involves careful design of a measurement sontrol program for each measurement technique and, in particular, for those techniques applied at the input and output measurement points. The four quantitative measures of systems performance--loss, time, detection probability, and false-alarm probability-are represented in Fig. 8. The Cusum performance surfaces are plotted as a function of probability of detection, total loss, and materials balance number for a 0.138 false-alarm probability $(3 \sigma)$. In

TABLE V

DETECTION SENSITIVITY

STRATEGY 1, UPAA 23

\begin{tabular}{|c|c|c|c|c|c|}
\hline \multirow{2}{*}{$\begin{array}{c}\text { Detection } \\
\text { Time } \\
\end{array}$} & \multirow[b]{2}{*}{$\begin{array}{l}\text { Number of } \\
\text { Materials } \\
\text { Balances } \\
\end{array}$} & \multicolumn{2}{|c|}{ Case 1} & \multicolumn{2}{|c|}{ Case 2} \\
\hline & & $\begin{array}{c}\text { Average Diversion } \\
\text { Per Balance } \\
(\mathrm{kg} \mathrm{Pu}) \\
\end{array}$ & $\begin{array}{l}\text { Total at Time } \\
\text { of Detection } \\
\text { (kg Pu) } \\
\end{array}$ & $\begin{array}{c}\text { Average Diversion } \\
\text { Per Balance } \\
(\mathrm{kg} \mathrm{Pu}) \\
\end{array}$ & $\begin{array}{l}\text { Total at Time } \\
\text { of Detection } \\
\text { (kg pu) } \\
\end{array}$ \\
\hline $4 \mathrm{~h}$ & 1 & 1.38 & 1.38 & 1.38 & 1.38 \\
\hline 1 day & 6 & 0.27 & 1.62 & 0.27 & 1.62 \\
\hline I wk & 42 & 0.14 & 5.84 & 0.07 & 2.95 \\
\hline $2 w k$ & 84 & 0.13 & 11.33 & 0.05 & 4.11 \\
\hline 1 month & .168 & 0.13 & 22.42 & 0.04 & 6.10 \\
\hline
\end{tabular}



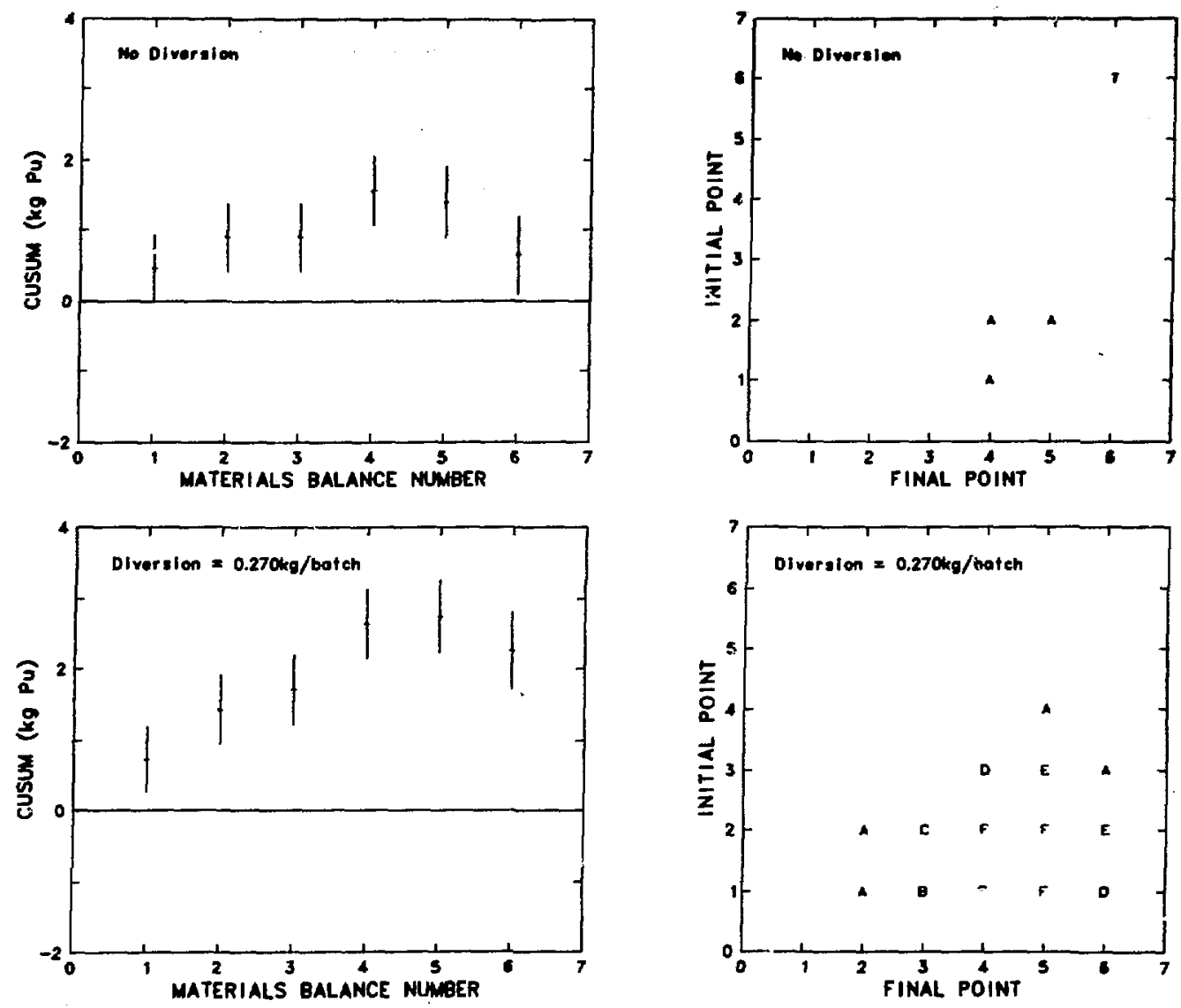

Fig. 5. Strategy 1, UPAA 2 3, Case 2, 1 day: Cusum and alarm charts.

evaluating the overall system performance, note that if the system were perfect, i.e., detection probability of one for all loss and all time, the performance surface would be a rectangular parallelepiped. In Fig. 8 the Cusum performance surfaces for Case 1 (upper) and Case 2 (lower) are compared. The systems performance improvement that is obtained by daily calibrations is eviderit by simply comparing the area above the 908 detection probability contour.

Examples of the analysis simulation results for strategy 1 are given in Figs. 5-7. Each figure shows cusum plots and the corresponding alarm chart for two cases: no diversion (upper) and uniform diversion (lower). Three examples are given for analysis windows of 1 day $(6$ balances), 1 wk (42 balances), and 1 month (168 balances). In all cases the diversion levels are the estimated detection sensitivities given in Table $\mathrm{V}$ for case 1.

For each Cusum chart, cumulative summations of dynamic materials balances are plotted sequentially with $1-\sigma$ error bars. Letter symbols on the associated alarmsequence charts indicate the length and significance of sequences of dynamic materials balances that generate alarms (Table IV).

Examination of the Cusum charts shows a daily trend. In any given day, the first through fifth balances show a positive trend, while the sixth bajance returns the Cusum to near zero. This occurs because the content of the vacuin systen that is used to recover spilled powder is measured once a day. Therefore, the materials balances that are taken when the vacuum is not measured indicate that a low-level 

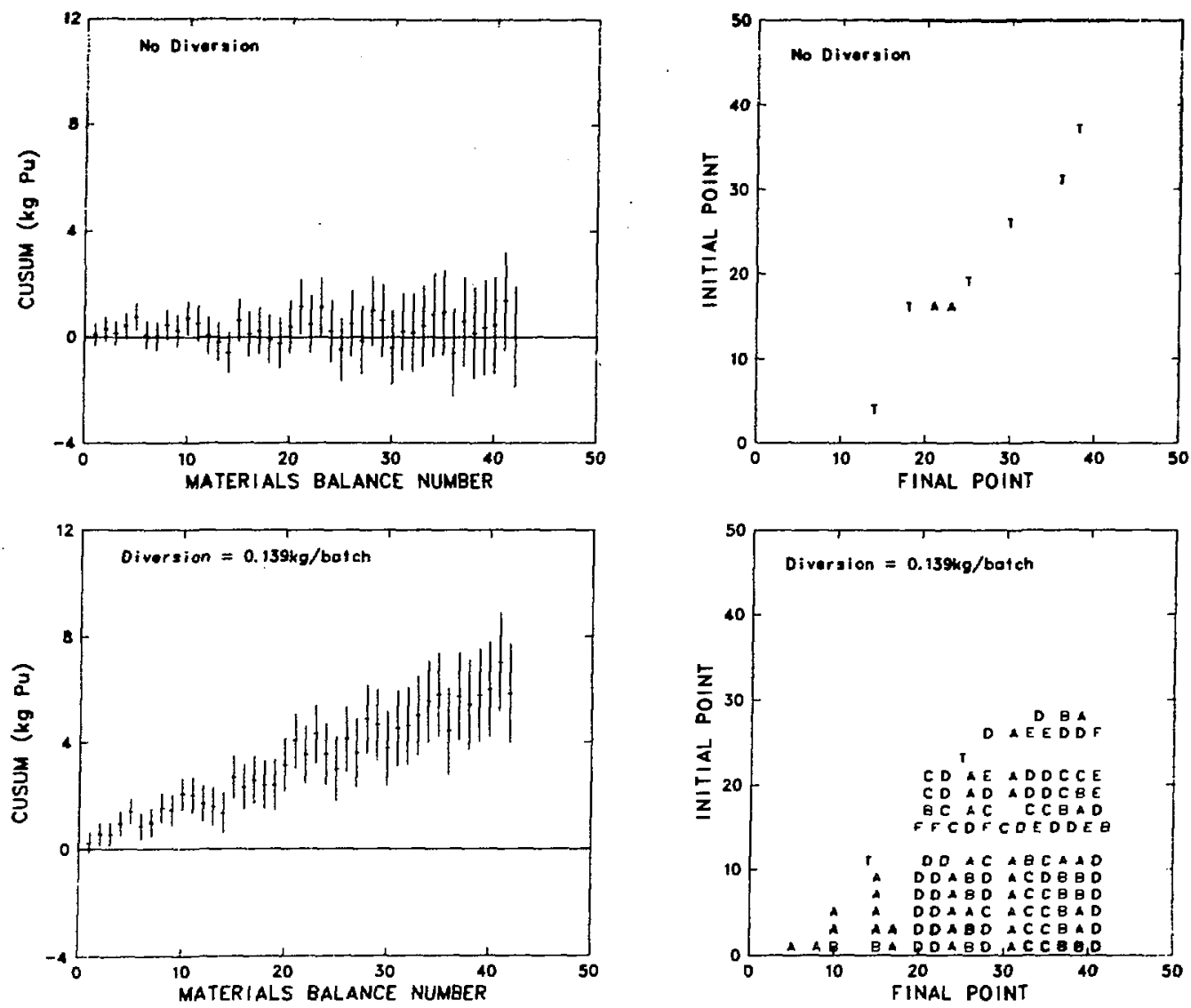

Fig. 6. Strategy 1, UPAA 2 3, Case 2, 1 week: Cusum and alarm charts.

"ioss" has occurred. Because of process variation and measurement uncertainty, this trend often gives alarms that occur near the diagonal of the alarm-sequence charts.

As this example indicates, the decision as to whether diversion has or has not occurred must be based on indications of the MMAS that are combined with knowledge of process behavior and operating history.

\section{B. Strategy 2}

In accounting Stategy 2, each process line is treated as two UPAAs in series (see Sec. III.B.2): UPAA 2 A, 2 B, 2 C--precipitation and calcination; UPAA $3 \mathrm{~A}, 3 \mathrm{~B}$, 3 c--reduction, stabilization, and screening.
The vacuum system presents more of a materials accounting problem in strategy 2 than in Strategy 1. Remember that to maintain process-line independence we have assumed that each process line has its own vacuum system. We have also assumed that the vacuum system is emptied and the material is measured once a day. In strategy 2 , when the material from the vacuum system is measured, we have two choices: (1) not to include any of the vacuum system material in the materials balance and (2) divide the material between UPAA 2 and 3 and include it in the last materiais balance of the day for each UPAA. Cusums for these two cases for UPAA 2 are given in Fig. 9. The division of material between JPAAs 2 and 3 must be based on plant operating experience. In the event that a spill 

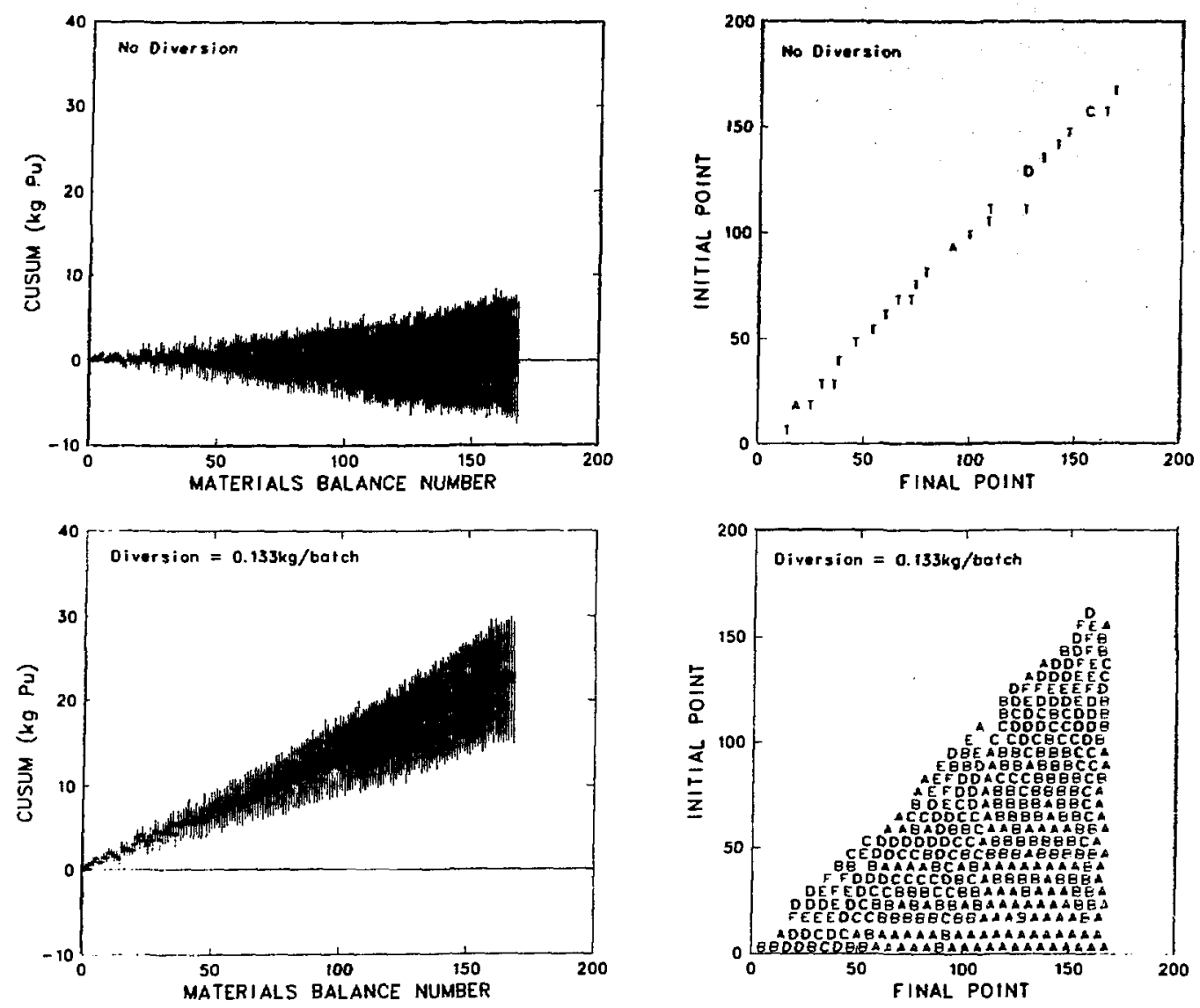

Fig. 7. Strategy 1, UPAA 2 3, Case 2, 1 month: Cusum and alarm charts.

occurs in one of the UPAAs, the apportionment would not be correct, resulting in missing material in one UPAA and too much material in the other UPAA. In such cases, it is easy to revert to strategy 1 , UPAA 23 in which the two UPAAs are combined.

In the analysis below, we have chosen the second approach because losses to the vacuum are too large to be included as an unmeasured side stream.

1. UPAA 2 A, 2 B, 2 C. A materials balance is taken every $4 \mathrm{~h}$ when a precipitator feed tank is empty. The balance includes one feed batch and two calciner primary filter product batches.

Dynamic materials accounting jetection sensitivities for periods from $4 \mathrm{~h}$ to 1 month are given in Table VI for two cases. In Case 1, no instrument calibrations are performed within the accounting period. In Case 2, the input concentration and the reduction container contents measuring instruments are calibrated daily. The behavior of the detection sensitivities is similar to that of strategy 1 , UPAA 23 . The single balance detection sensitivity is better than that of strategy 1 because the in-process inventory is smaller. The sensitivities for periods of 1 day and longer are worse because the intermediate transfer measurement is of poorer quality than the product measurement.

2. UPAA 3 A, 3 B, 3 C. A materials balance is closed every $2 \mathrm{~h}$ around each batch that is produced by the process line. Dynamic materials accounting sensitivities 

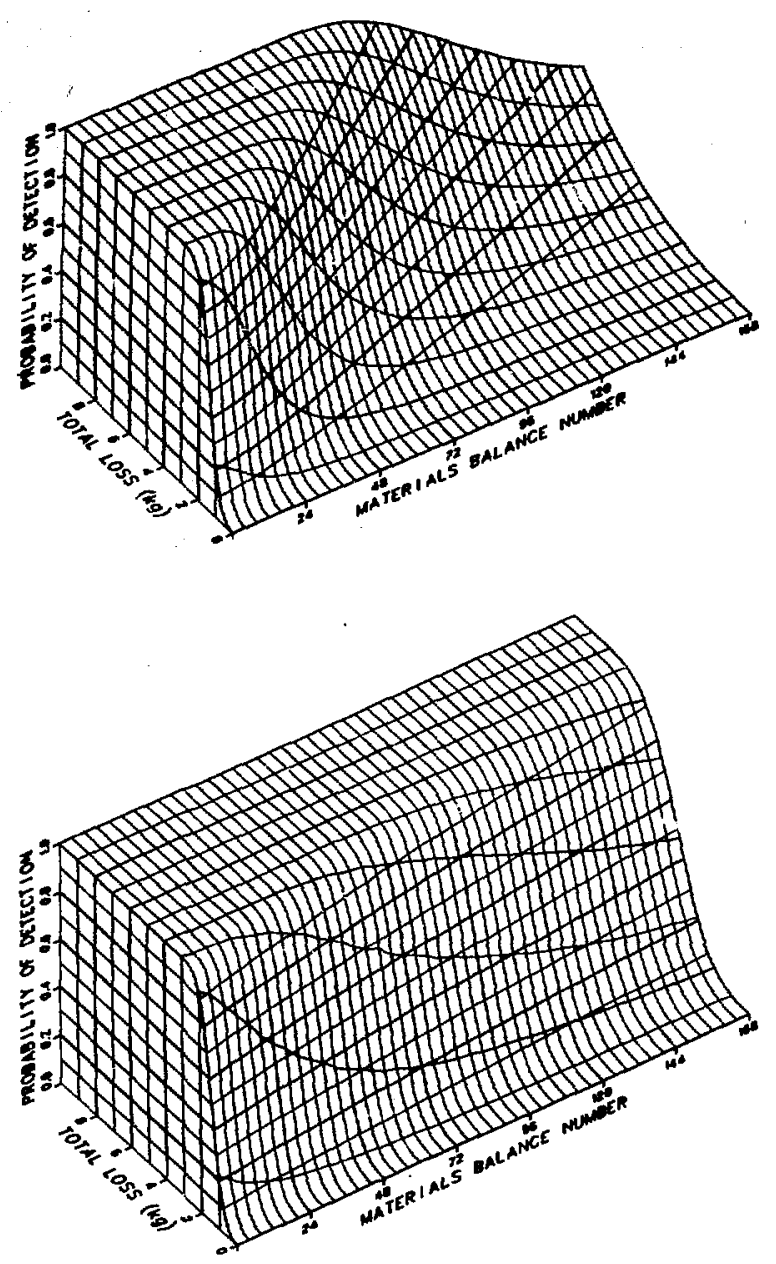

Fig. 8. Strategy 1, UPAA 23,1 month, Cusum performance surfaces: Case 1 (upper), Case 2 (lower).

for periods from 2 h to 1 month are given in Table VII for two cases. In Case 1, no instrument calibrations are performed within the accounting period. In Case 2, the reduction container and product container contents measuring instruments are calibrated daily. Again, the detection sensitivities behave the same as those in strategy 1. In this case the single-balance detection sensitivity is significantly better because the balance is taken for a single batch and because the in-process inventory in a reduction-stabilization station is quite small.
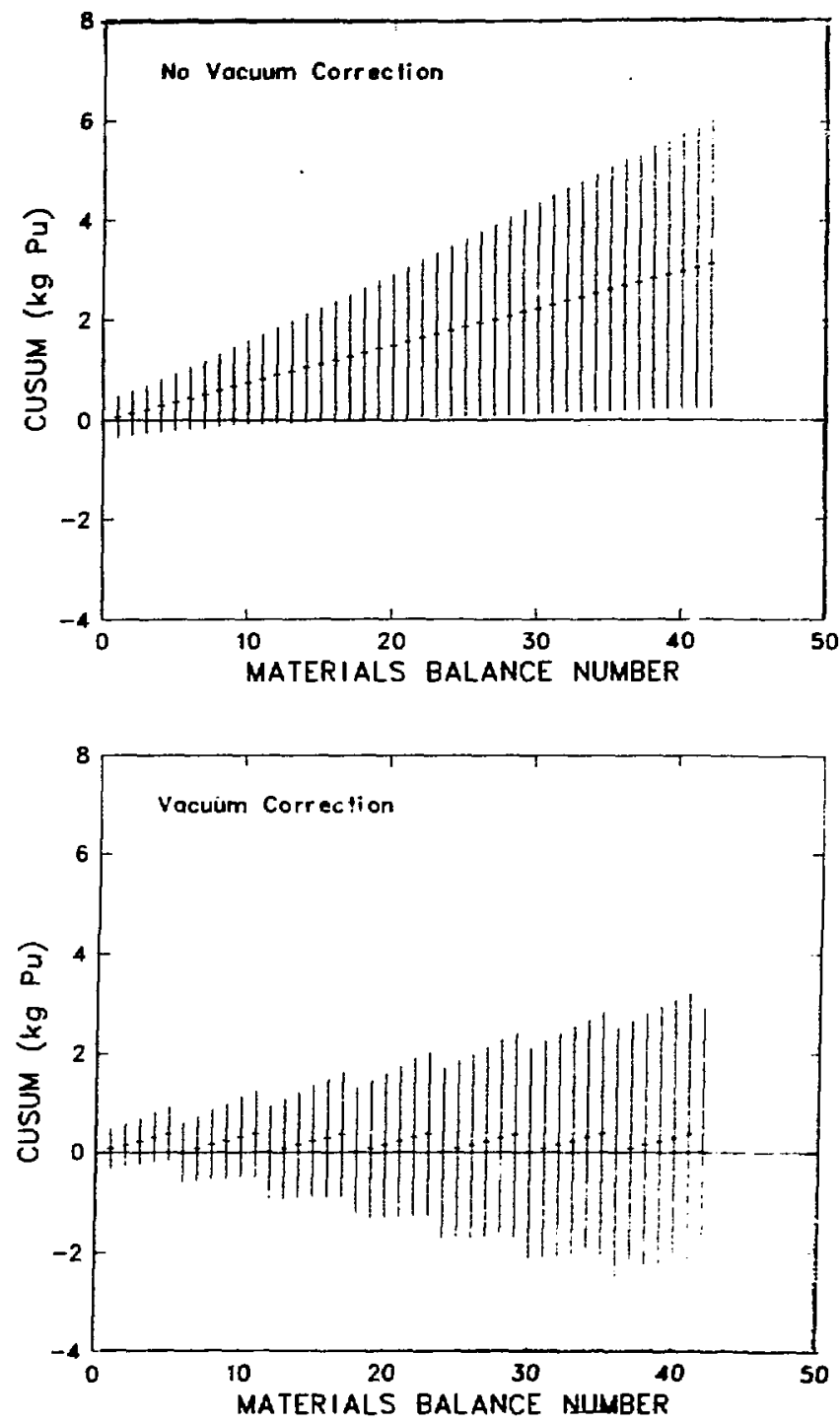

Fig. 9. Strategy 2, UPAA 2, 1 week, Cusum chart: witiout vacuum measurement (upper), with distributed vacuum measur ement (lower).

VI. CONCLUSIONS

In this study we have seveloped and evaluated a conceptual design of a dynamic MuAs for the modified Coprecal process. In the proposed MMAs, conventional accounting methods are augmented by dynamic accounting, where the MBAs are partitioned into discrete accounting envelopes called 


\begin{tabular}{|c|c|c|c|c|c|}
\hline \multirow[b]{2}{*}{$\begin{array}{l}\text { Detection } \\
\text { Time } \\
\end{array}$} & \multirow[b]{2}{*}{$\begin{array}{l}\text { Number of } \\
\text { Materials } \\
\text { Balances } \\
\end{array}$} & \multicolumn{2}{|c|}{ Case 1} & \multicolumn{2}{|c|}{ Case 2} \\
\hline & & $\begin{array}{c}\text { Average Diversion } \\
\text { Per Balance } \\
(\mathrm{kg} \quad \mathrm{Pu}) \\
\end{array}$ & $\begin{array}{l}\text { Total at Time } \\
\text { of Detection } \\
\text { (kg Pu) } \\
\end{array}$ & $\begin{array}{c}\text { Average Diversion } \\
\text { Per Balance } \\
(\mathrm{kg} \text { Pu }) \\
\end{array}$ & $\begin{array}{l}\text { Total at Tise } \\
\text { of Detection } \\
(\mathrm{kg} \text { Pu) } \\
\end{array}$ \\
\hline $2 \mathrm{~h}$ & 1 & 1.29 & 1.29 & 1.29 & 1.29 \\
\hline 1 day & 6 & 0.31 & 1.87 & 0.31 & 1.87 \\
\hline 1 wk & 42 & 0.21 & 8.78 & 0.10 & 4.03 \\
\hline $2 w k$ & 84 & 0.20 & 17.22 & 0.07 & 5.71 \\
\hline 1 month & 168 & 0.20 & 34.27 & 0.05 & 8.23 \\
\hline
\end{tabular}

UPAAs. Materials balances are' obtained around these UPAAs as the plant is operating. Partitioning and taking frequent materials balances localizes materials loss in both space and time. Therefore, to escape detection by the MMAs, a potential divertor is forced to steal small quantities of material from several locations for a long time, thus increasing the number of times he must pass through surveillance systems.

The measurement requirements for dynamic materials accounting have been identified (Sec. III.A). The input accountability measurements are based on well-developed conventional analysis techniques. The product measurements are based on tested NDA techniques that have not been evaluated for mixed-oxide powders. The NDA product measurenents are required to close the materials balances in nearreal-time and do not replace the normal weight and chemical analysis of a sample. Therefore, there will be continuous verification of the product measurements. All principal process vessels are instrumented using NDA techniques to determine their in-process inventory. These measurement systems have not been tested and evaluated on the type of materials, geometry, and operating environment that is encountered in the coprecal process.

Dynamic materials accounting strategies have been developed and evaluated. Detection sensitivities for the modified Coprecal process, the original coprecal

TABLE VII

DETECTION SENSITIVITY
STRATEGY 2, UPAA 3

\begin{tabular}{|c|c|c|c|c|c|}
\hline \multirow[b]{2}{*}{$\begin{array}{l}\text { Detection } \\
\text { Time }\end{array}$} & \multirow[b]{2}{*}{$\begin{array}{l}\text { Number of } \\
\text { Materials } \\
\text { Balances } \\
\end{array}$} & \multicolumn{2}{|c|}{ Case 1} & \multicolumn{2}{|c|}{ Case 2} \\
\hline & & $\begin{array}{c}\text { Average Diversion } \\
\text { Per Balance } \\
(\mathrm{kg} \mathrm{Pu}) \\
\end{array}$ & $\begin{array}{l}\text { Total at Time } \\
\text { of Detection } \\
(\mathrm{is} \mathrm{pu})\end{array}$ & $\begin{array}{c}\text { Average Diversion } \\
\text { Per Balance } \\
(\mathrm{kg} \mathrm{Pu}) \\
\end{array}$ & $\begin{array}{l}\text { Total at Tine } \\
\text { of Detection } \\
(\mathrm{kg} \mathrm{Pu}) \\
\end{array}$ \\
\hline $4 h$ & 1 & 0.25 & 0.25 & 0.25 & 0.25 \\
\hline 1 day & 6 & 0.13 & 1.54 & 0.13 & 1.54 \\
\hline $1 w k$ & 42 & 0.11 & 9.63 & 0.05 & 4.09 \\
\hline $2 w k$ & 84 & 0.11 & 19.07 & 0.03 & 5.80 \\
\hline 1 month & 168 & 0.11 & 37.93 & 0.02 & 8.23 \\
\hline
\end{tabular}


process, and the oxalate (III) conversion process are given in Table vIII. The detection sensitivities in each case are for the accounting strategy that includes an entire process line in a single accounting area. The process lines have the same throughput.

In comparing the detection sensitivities of the modified and original coprecal processes, note that:

1) The single-balance detection sensitivity for the modified process is not as good as that of the original process because the inprocess inventory in the modified process is larger. The larger inventory results from the addition of a filter system for each calciner.

2) Detection sensitivities for accounting periods greater than 1 day have been improved in the modified process because the input transfer measurements have been improved by adding aliquot tanks.

In comparing the detection sensitivities of the modified coprecal process with the oxalate (I.II) conversion process, note that detection sensitivities for oxalate (III) are significantly better for all accounting periods. There are two reasons :or this: (1) the in-process inventory in the oxalate (III) process is smaller; and (2) there are no scrap or vacuum measurements in the oxalate (III) process; these measurements make a significant contribution to the materials balance uncertainty.

The following recomendations are essential for effective dynamic materials accountability in the modified coprecal process.

- Measurement control programs that identify and control the sources of error must be instituted. If correlated errors in transfer measurements are not controlled, then the detection sensitivities will be unacceptably degraded.

- Provision must be made for measuring the plutonium in-process inventory in process equipment. Inprocess inventory measurements about 108 or better should be satisfactory.

- Large neutron detection systems for measuring the plutonium inventory in process vessels and in large, annular filters should be built and demonstrated.

- Careful consideration should be given to reducing the in-process inventory.

\section{TABLE VIII}

DETECTION SENSITIVITY COMPARISON-MODIFIED COPRECAL, ORIGINAL COPRECAL, OXALATE (III)

\begin{tabular}{|c|c|c|c|c|c|c|}
\hline \multirow[b]{2}{*}{$\begin{array}{l}\text { Detection } \\
\text { Time }\end{array}$} & \multicolumn{2}{|c|}{ Modified Coprecal } & \multicolumn{2}{|c|}{ Original Coprecal } & \multicolumn{2}{|c|}{ Oxalate (III) } \\
\hline & $\begin{array}{c}\text { Average per } \\
\text { Balance }(4 \mathrm{~h}) \\
(\mathrm{kg} \text { Pu }) \\
\end{array}$ & $\begin{array}{l}\text { Total at } \\
\text { Detection } \\
\text { (kg Pu) }\end{array}$ & $\begin{array}{c}\text { Average per } \\
\text { Balance }(2 \mathrm{~h}) \\
(\mathrm{kg} \mathrm{Pu}) \\
\end{array}$ & $\begin{array}{l}\text { Total at } \\
\text { Detection } \\
\text { (kg Pu) }\end{array}$ & $\begin{array}{c}\text { Average per } \\
\text { Balance }(1.3 \mathrm{~h}) \\
(\mathrm{kg} \mathrm{Pu}) \\
\end{array}$ & $\begin{array}{l}\text { Total at } \\
\text { Detection } \\
\text { (kg Pu) } \\
\end{array}$ \\
\hline 1 balance & 1.4 & 1.4 & 1.2 & 1.2 & 0.4 & 0.4 \\
\hline 1 day & 0.27 & 1.6 & 0.13 & 1.6 & 0.02 & 0.5 \\
\hline 1 wk & 0.07 & 3.0 & 0.04 & 3.7 & 0.01 & 1.7 \\
\hline 1 month & 0.04 & 6.1 & 0.03 & 8.4 & 0.007 & 3.9 \\
\hline
\end{tabular}


- Methods of decreasing the amount of scrap that is generated should be investigated. Measurements of scrap could probably be improved if the Inconel shot is retained within the calciners.

- Cònsideration should be given to adding a precipitator to feed each calciner. This would provide better process fiducial for taking materials balances.

\section{ACKNOWLEDGMENTS}

The cooperation and assistance of L. A. Heinrich of Savannah River Laboratory and J. H. Radke and J. E. Eargle of Savannah River Plant are gratefully acknowledged. Thanks are due to our colleagues, D. D. Cobb, R. J. Dietz, E. A. Hakkila, D. Stirpe, and D. B. Smith for their helpful suggestions. We wish to express our gratitude to $\mathrm{S}$. L. Klein for the preparation of the manuscript and to $D$. P. Martinez, M. S. Scott, I. Bonner, and M. J. Roybal for the preparation of the graphics.

\section{REFERENCES}

1. H. A. Dayem, D. D. Cobb, R. J. Dietz, E. A. Hakkila, E. A. Kern, E. P. Schelonka, J. P. Shipley, and D. B. Smith, "Coordinated Safeguards for Materials Management in a UraniumPlutonium Nitrate-to-oxide Coconversion Facility: Coprecal," Ios Alamos Scientific Iaboratory report IA-7521 (February 1979).

2. Savannah River Plant document DPSTDAFCT-77-10-TL (November 1977).

3. H. A. Dayem, "Coprecal: process kodifications for Safeguards Improvement, I. Addition of Aliquot Tanks (Preliminary Analysis)," Los Alamos Scientific Laboratory report LA-7746-MS (June 1979 ).

4. J. C. Eargle, Savannah River plant, personal communication, December 1978 .
5. J. H. Radke, Savannah River Plant, personal comunication, January 1979.

6. T. R. Canada, D. G. Langner, J. L. Parker, and $E$. A. Hakkila, "Galm- and X-Ray Techniques for the Mondestructive Assay of Special Nuclear Material in Solution," in "Coordinated Safeguards for Materials Management in a Fuel Reprocessing plant," Los Alamos Scientific Laboratory report LA-6881 (September 1977), Vol. II, App. A.

7. G. R. Keepin and H. J. Maraman, "Kondestructive Assay Technology and InPlant Dynamic Materials Control-DYMAC," in Safeguarding Nuclear Materials, Proc. Symp., Vienna, October 1975 (Interriational Atomic Energy Agency, Vienna, 1976), IAEA-SM-201/32, Vol. I, pp. 304-320.

8. R. H. Augustson, N. Baron, R. F. Ford, W. Ford, J. Hagen, T. R. Li, R. S. Marshall, Y. S. Reams, W. R. Severe, and D. G. Shirk, "A Development and Demonstration Program for Dynamic Nuclear Materials Control," in Nuclear Safeguards Technology 1978, Proc. Symp., Vienna, October 2-6, 1978 (International Atomic Energy Agency, Vienna, 1979), IAEA-SM-231-101, Vol. I, pp. 445-462.

9. J. P. Shipley, D. D. Cobb, R. J. Dietz, M. L. Evans, E. P. Schelonka, D. B. Smith, and R. B. Walton, "Coordinated Safeguards for Materials Management in a Mixed-oxide Fuel Facility," Los Alamos Scientific Laboratory report LA-6536 (February 1977).

10. E. A. Hakkila, D. D. Cobb, H. A. Dayem, R. J. Dietz, E. A. Kern, E. P. Schelonka, J. P. Shipley, D. B. Smith, R. H. Augustson, and J. w. Barnes, "Coordinated Safeguards for Materials Management in a Fuel Reprocessing Plant," Los Alamos Scientific Laboratory report LA-68B1 (September 1977).

11. D. D. Cobb, J. L. Sapir, ¿. A. Kern, and R. J, Dietz, "Concepts for Inventory Verification in Critical Facilities," Los Alamos Scientific Laboratory report LA-7315 (December 1978).

12. H. A. Dayem, D. D. Cobb, R. J. Dietz, E. A. Hakkila, E. A. Rern, J. P. Shipley, D. B. Smith, and D. F. Bowersox, "Coordinated Safeguards for Materials Management in a Nitrate to Oxide Conversion Facility," Los Mlanos Scientific Laboratory report LA-7011 (April 1978). 
13. E. A. Hakkila, D. D. Cobb, H. A. Dayem, R. J. Dietz, E. A. Kern, J. T. Markin, J. P. Shipley, J. H. Barnes, and $L$. A. Scheinman, Materials Management in an Internationally. Safeguarded Fuels Reprocessing Plant, Vol. II," Los Alamos Scientific Laboratory report $\mathrm{LA}-8042$ (in press).

14. D. D. Cobb and D. B. Smith, "Modeling and Simulation in the Design and Evaluation of Conceptual Safeguards Systems," Nucl. Mater. Manage. VI(3) 171-184 (1977).

15. T. Naylor, J. L. Balintfy, D. $S$. Burdick, and $\mathrm{K}$. Chu, Computer Simulation Techniques (John wiley and Sons, New Y.ork, 1966).

16. J. Rleijnen, Statistical Techniques in simulation (Marcel Dekker, New York, 1974).

17. A. Pritsker, The GASP IV Simulation Language (Wiley-Interscience, 1976).

18. J. P. Shipley, "Decision Analysis for Nuclear Safeguards," in Nuclear Safeguards Analysis - Nondestructive and Analytical Chemical Techniques, E. A. Hakkila, Editor, Am. Chem. Soc., Washington, DC (1978), pp. 34-64.
19. J. P. Shipley, "Decision Analysis for Dynamic nccounting of Muclear Material," in Analytical Methods for Safeguards and Accountability keasurement of Special Nuclear Naterial, H. T. Yolken and J. E. Bullard, Eds., NBS Special Publication 528 (Hovember 1978), pp. 83-97.

20. R. E. Ralman, "A New Approach to Linear Filtering and Prediction Problens," Trans. ASME J. Basic Eng. B2D, 34-45 (March 1960).

21. R. E. Kalman and R. S. Bucy, "New Results in Linear Filtering and Prediction Theory," Trans. ASwE J. Basic Eng. 83D, 95-108 (March 1961).

22. D. D. Cobb and J. P. Shipley, "Performance Analysis of Nuclear Materials Accounting systems," Nucl. Mater. Manage. VIII(2), 81-92 (1979).

23. J. P. Shipley, "Efficient Analysis of Dynamic Materials Accounting Data," Nucl. Mater. Manage. VII, 355-366 (1978).

24. K. B. Stewart, "The Loss Detection Powers of Four Loss Estimators, "Nucl. Mater. Manage. VII(3), 74-80 (1978). 


\section{APPENDIX \\ DYNAMIC MODEL OF THE COCONVERSION PROCESS}

\section{INTRODUCTION}

The design and evaluation of the MMAs is based on computer simulations of the reference coconversion facility. Modeling and simulation techniques permit prediction of the behavior of materials flows over the range of possible operating conditions and provides a means for rapid accumulation of data for relatively long operating periods. Alternative materials measurement strategies and safeguards data-analysis algorithms are readily compared. In principle, the necessary data could be obtained from experiments on test loops and mockups of plant operation, but this is both time consuming and expensive. Carefully selected test loops can be used more effectively to validate the computer models and to test portions of the final MMAS design.

Modeling and simulation have been used extensively in advanced accounting studies of chemical separations (see Ref. 1, Sec. VI and Apps. E and G), plutonium nitrateto-oxide conversion facilities (see Ref. 2, Sec. IV and App. A), and mixed-oxide fuel fabrication (see Ref. 3, Sec. IV and App. D). This approach requires: 4

1) A detailed dynamic model of the process based on actual design data,

2) Simulation of the model process on a digital computer,

3) A model for each measurement system,
4) Simulation of accountability measurements applied to nuclear material flow and in-process inventory data generated using the model process, and

5) Evaluation of simulated data from various materials accounting strategies.

This appendix describes MODEL, a computer code written to simulate the dynamic behavior of the coprecal process under anticipated normal operating conditions.

\section{THE MODEL PROCESS}

The Coprecal model is based on an original GE design, ${ }^{5}$ which was modified by Savannah River Plant (SRP), Savannah River Laboratory (SRL), and duPont Engineering. The process converts uraniumplutonium-nitrate solution to mixed uranium-plutonium-oxide powder. Coprecipitation in ammonium hydroxide is followed by calcination of the entire precipitator product. The calcined powder is batch transferred to reduction-stabilization, $\mathrm{UO}_{3}$ is reduced to $\mathrm{UO}_{2}$, stabilized to $\mathrm{UO}_{2} .07$ ' then screened and canned. The reference facility has a design throughput of $117 \mathrm{~kg}$ plutonium/day through three parallel process lines. The process is described in detail in sec. II of this report. 
Materials transfers from a feed tank

Operation of the model process is simulated by standard Monte carlo techniques developed for dynamic systems.6,7 The model is divided into continuous and batch operations. The continuous portion includes the precipitator feed tanks, the precipitator, the calciners, and the calciner primary and secondary filters. The receipt tanks, reduction stabilization, vacuums, and screening are batch operated. riming for the batch processes is controiled by the precipitator feed tanks. Only one feed tank feeds the precipitator at any one time. Approximately $4 \mathrm{~h}$ are required to empty a feed tank. The emptying of a feed tank schedules the batch processes that take place in the next $4 \mathrm{~h}$ prior to another feed tank becoming empty. For example, if a precipitator feed tank becomes empty at $T h$, this triggers the following batch operations.

1) $T+0 h$

a) Transfer of a full reduction container from a reductionstabilization station to screening.

b) Transfer of a full reduction container from a calciner primary filter to the reductionstabilization station in step a. Note that the batch operations in the four reductionstabilization stations and the screening take place every $8 \mathrm{~h}$ with the batches staggered at 2-h intervals.

c) Fill a receipe-accountability tank.

2) $\mathrm{T}+2 \mathrm{~h}$

Steps $a$ and $b$ from above.

3) $T+3 h$

Transfer a batch from a receiptaccountability tank to an empty precipitator feed tank. to the precipitator, from the precipitator to the calciners, from the calciners to the calciner primary filters, and from the calciner primary filters to the calciner secondary filters are modeled with continuous flows. In each process line, a single precipitator feeds all four calciners simultaneously.

The dynamics of each individual unit process, i.e., feed tank, precipitator, calciner, etc., are governed by the continuity equation

$$
T(t)+I(t-1)=I(t),
$$

where

$\begin{aligned} T(t)= & \text { sum of all input tranfers } \\ & \text { minus the sum of output } \\ & \text { transfers to the unit pro- } \\ & \text { cess over the interval } \\ & t-1 \text { to } t . \\ I(t-1)= & \text { inventory at time } t-1 . \\ I(t)= & \text { inventory at time } t .\end{aligned}$

The net transfer can include continuous flow streams, batch transfers, or a combination of both. The time dependence of the continuous streams is linear over time steps chosen for the simulation (30 min). The continuity equation is satisfied at all times in the continuous unit processes and is updated every $4 \mathrm{~h}$ for the batch processes.

Random variation in the process is determined by the statistics selected for the independent process variables. The variation of each variable is uniform over a given interval. The nominal value and the interval of uniform distribution for each of the independent process variables is summarized in Table A-I.

Dependent process variables are calculated sirectly from the independent variables in Table A-I. Nominal values for these dependent process variables over a 


\begin{tabular}{|c|c|c|}
\hline Identification & Nominal Value & $\begin{array}{l}\text { Range } \\
(8)\end{array}$ \\
\hline $\begin{array}{l}\text { Receipt tanks } \\
\text { Volume } \\
\text { Concentration }\end{array}$ & $\begin{array}{l}162.7 \mathrm{~L} \\
0.0399 \mathrm{~kg} \mathrm{Pu} / L\end{array}$ & $\begin{array}{l}1 \\
1\end{array}$ \\
\hline $\begin{array}{l}\text { Precipitator feed tanks } \\
\text { Output flow rate }\end{array}$ & $40.675 \mathrm{~L} / \mathrm{h}$ & 1.5 \\
\hline $\begin{array}{l}\text { Precipitator in-process } \\
\text { inventogy }\end{array}$ & $1.06 \mathrm{~kg} \mathrm{Pu}$ & 7 \\
\hline $\begin{array}{l}\text { Calciner in-process } \\
\text { inventory }\end{array}$ & $0.9 \mathrm{~kg} \mathrm{Pu}$ & 10 \\
\hline $\begin{array}{l}\text { Calciner primary filter } \\
\text { Holdup } \\
\text { Output to vacuum }\end{array}$ & $\begin{array}{l}0.75 \mathrm{~kg} \mathrm{Pu} \\
0.0375 \mathrm{~kg} \mathrm{Pu} / \text { batch }\end{array}$ & $\begin{array}{l}20 \\
11\end{array}$ \\
\hline $\begin{array}{l}\text { Reduction-stabilization } \\
\text { primary filter } \\
\text { Flow rate to final } \\
\text { filter } \\
\text { Holdup } \\
\text { Output to vacuum }\end{array}$ & $\begin{array}{l}0.0002 \mathrm{~kg} \mathrm{Pu} / \mathrm{h} \\
0.2 \mathrm{~kg} \mathrm{Pu} \\
0.0375 \mathrm{~kg} \mathrm{Pu} / \text { batch }\end{array}$ & $\begin{array}{r}5 \\
10 \\
11\end{array}$ \\
\hline Screening scrap output & $0.25 \mathrm{~kg} / \mathrm{batch}$ & 2 \\
\hline
\end{tabular}

28-day simulation are given in Table A-II. As seen from Table A-II, some of the dependent process variables have nominal values over a given range. In the case of the reduction container at the calciner primary filter, the reduction container is empty when it is first placed at the primary filter, and $8 \mathrm{~h}$ later, upon removal from the primary filter, it contains 3.244 $\mathrm{kg} \mathrm{Pu}$. The secondary and final filters are empty at the beginning of the simulation, and after 28 days, they contain 0.135 and $0.133 \mathrm{~kg} \mathrm{Pu}$, respectively.

IV. THE MODEL COMPUTER CODE

A general purpose process modeling code, MODEL, developed by the LASL Q-4 Safeguards Group, has been used to simulate the model Coprecal process. MODEL was written in FORTRAN and uses the GASP IV simulation package ${ }^{8}$ for event scheduling. The program is run on a PRIME 400 computer and requires 265000 words of 16-bit memory. A typical 28-day Coprecal simulation requires $\backsim 30 \mathrm{~s}$ of computer time. The general purpose GASP-IV simulation code has been simplified for direct application to process modeling. Most of the GASP IV input/output routines have been removed, and the size of the arrays have been adjusted to satisfy the particular needs of the process modeling problen. These simplifications have made the code easier to use and have resulted in a considerable reduction in computer memory requirement.

In applying the MODEL code to the Coprecal process, each of the individual unit processes represented by the rectangular boxes in Fig. 2, Sec. II is modeled by a separate subroutine. The remaining portion of the rODEL code handles the input 
In the Coprecal simulation, the volume of material in the precipitator feed tanks is modeled as a state variable. GASP-IV then integrates the tank output flow rate until the tank becomes empty. This is the state event that triggers the scheduling of the next set of discrete process events such as filling a receipt tank, transfer$r$ ing a reduction container from a calciner primary filter to reduction-stabilization, and transferring a reduction container from reduction-stabilization to screening.

\section{EXAMPLES}

Figures A-2 through A-11 are examples from a 48-h period of simulated process operation. Event times are established by switching the precipitator feed tanks at nominal $4-h$ intervals.

Figure A-2 shows the volume and concentration of a single receipt tank. This tank is initially full, and at $t=7 \mathrm{~h}$ its contents are transferred into a precipitator feed tank. At $t=8 \mathrm{~h}$ the receipt tank receives another batch from chemical separations. These events are repeated on an 8-h cycle.

The volume and concentration for a precipitator feed tank are shown in Fig. A-3. This tank is initially full and is feeding the precipitator. Flow from the tank is at a rate of $40.675 \pm 0.610 \mathrm{~L} / \mathrm{h}$. At approximately $t=4 \mathrm{~h}$ the tank becomes empty. Three hours later, at $t=7 \mathrm{~h}$, the feed tank is filled from the receipt tank, and at $t=8 \mathrm{~h}$ the tank again begins to feed the precipitator, repeating the cycle.

Figure A-4 shows the precipitator in-process inventory. The inventory is controlled between 20.098 and $0.113 \mathrm{~kg} \mathrm{Pu}$.

The operation of a single calciner station is shown in Figs. A-5 through A-8. The calciner in-process inventory (after a reduction container is disconnected) is constrained over the range $0.81-0.99 \mathrm{~kg} \mathrm{Pu}$

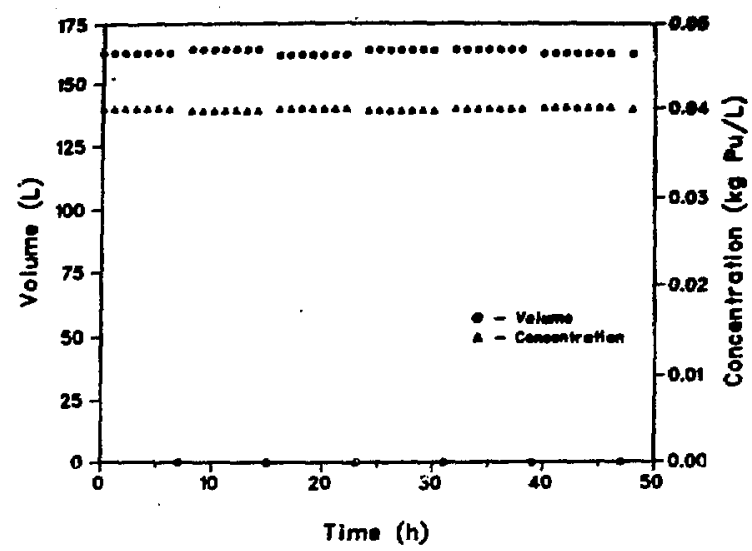

Fig. A-2. Receipt tank volume and concentration.

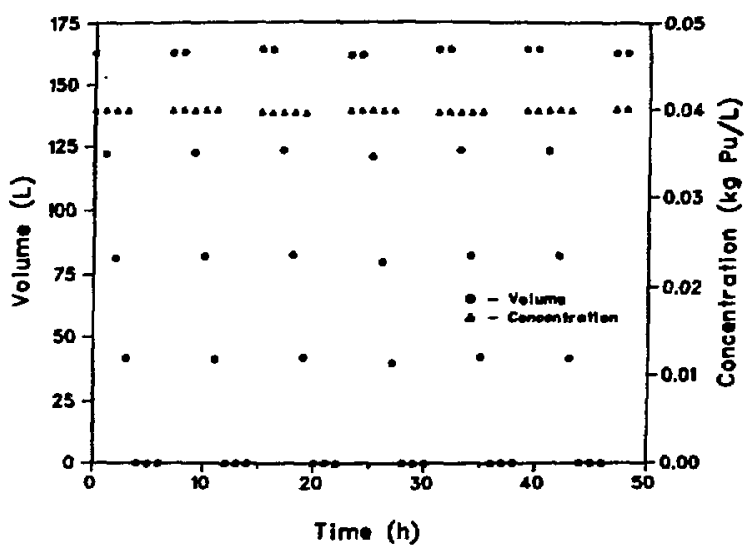

Fig. A-3. Feed tank volume and concentration.

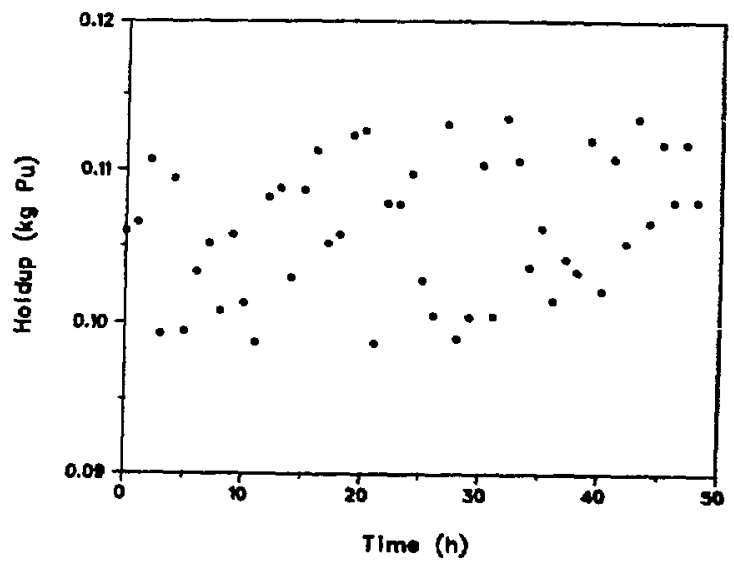

Fig. A-4. Precipitator in-procesa inventory. 


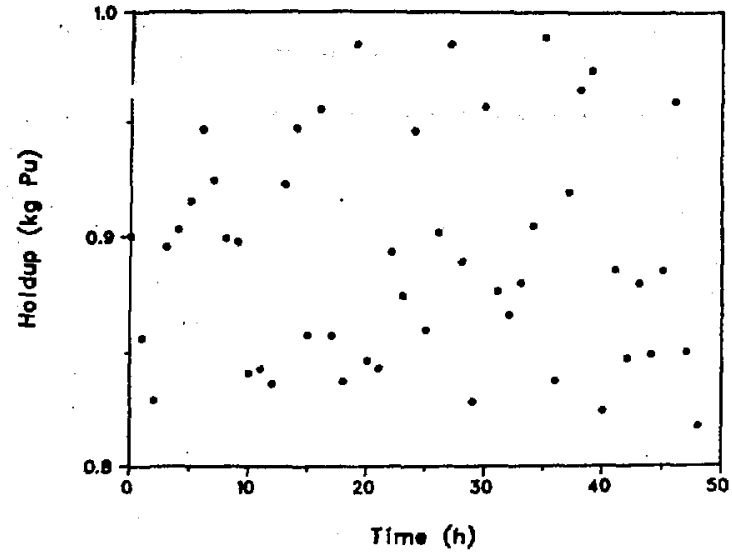

Fig. A-5. Calciner in-process inventory .

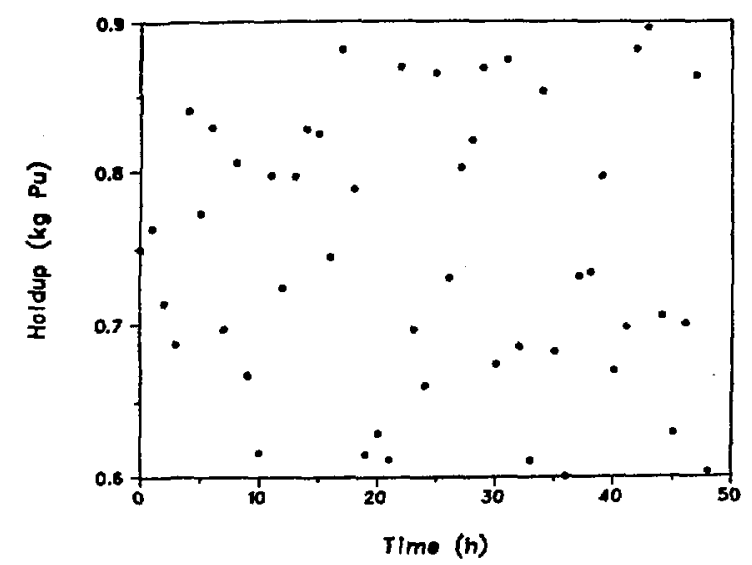

Fig. A-6. Calciner primary filter in-process inventory.

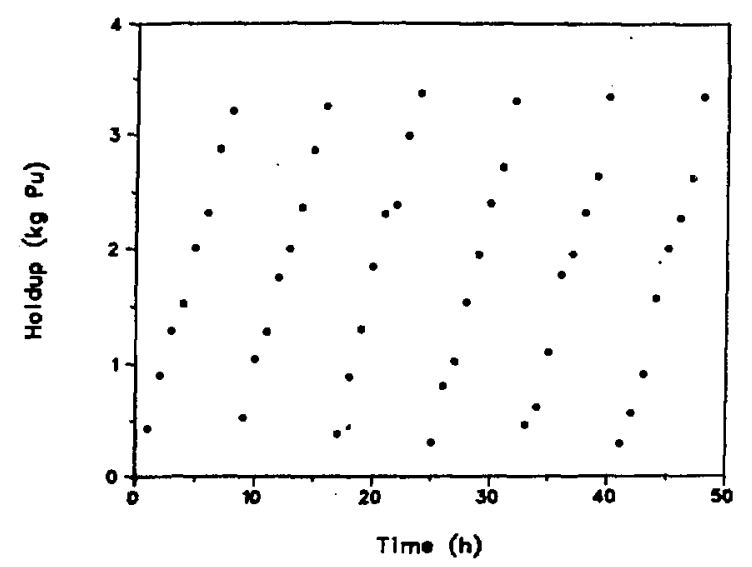

Fig. A-7. Calciner reduction container content.

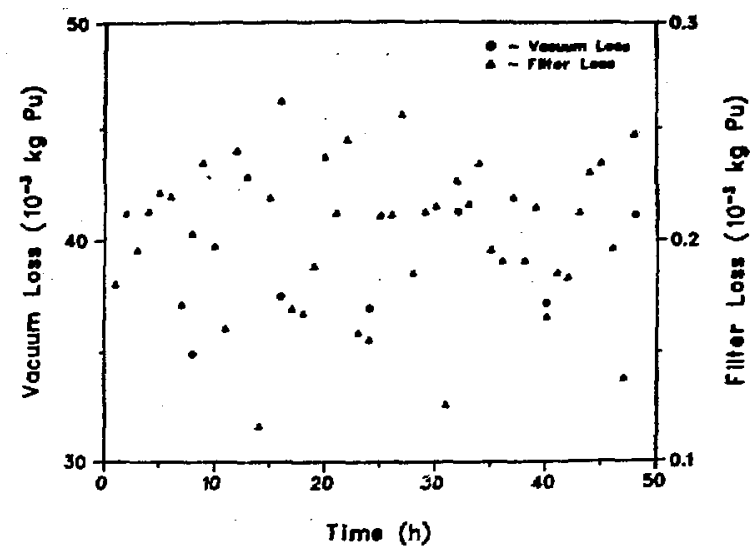

Fig. A-8. Calciner primary filter losses: vacuum and final filter.

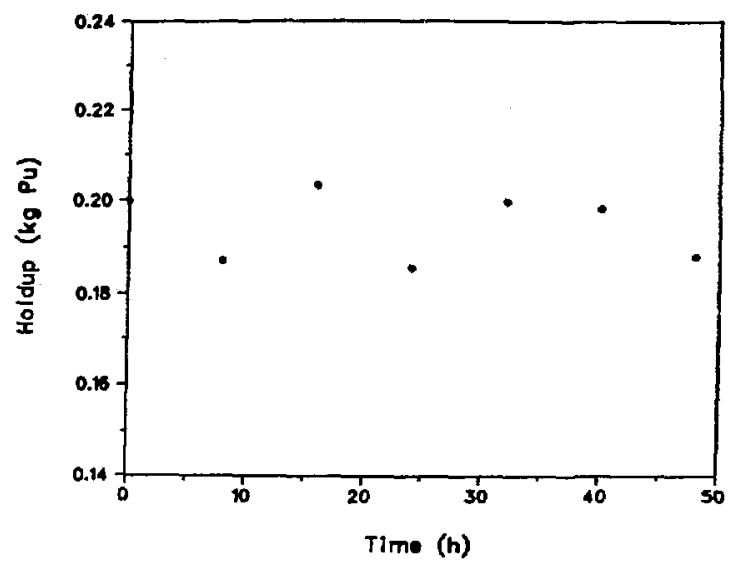

Fig. A-9. Reduction-stabilization primary filter holdup.

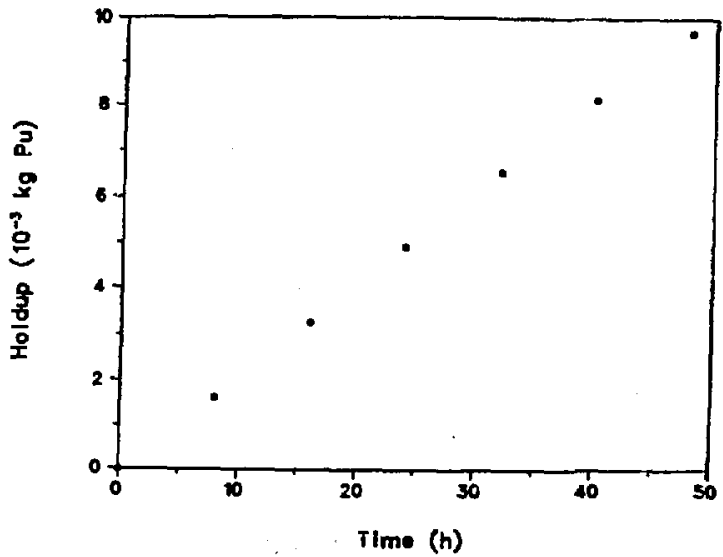

Fig. A-10. Reduction-stabilization final Filter holdup. 


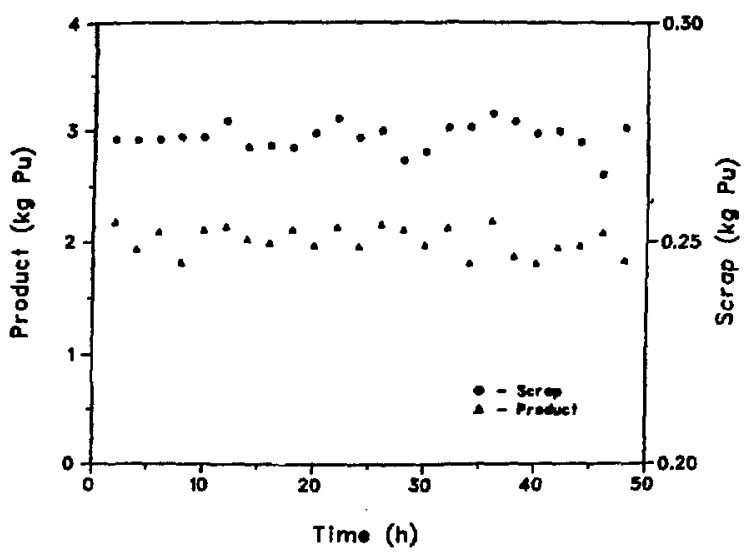

Fig. A-11. Screen output: product and scrap.

(Fig. A-5). The calciner primary filter in-process inventory is constrained over the range $0.60-0.90 \mathrm{~kg}$ Pu (Fig. A-6). At the start of the simulation, the reduction container at the calciner station is empty. As shown in Fig. A-7, the container is filled over an $8-\mathrm{h}$ interval to a $\mathrm{Pu}$ content of $\sim 3.2 \mathrm{~kg}$. At the end of $8 \mathrm{~h}$, the reduction container is transferred to the reduction-stabilization station and is replaced at the calciner station by an empty reduction container. Figure A-8 shows the calciner primary filter losses to the vacuum and the secondary filter. The loss to the secondary filter in the figure is the cummulative loss over a $1-h$ interval, although the loss is actually continuous. The vacuum loss takes place at $8-\mathrm{h}$ intervals to coincide with the transfer of the reduction container to the reduction-stabilization station.

Figures $A-9$ and $A-10$ represent the operation of the reduction-stabilization station, where each batch requires $\sim 8 \mathrm{~h}$. The holdup in the reduction-stabilization primary filter is controlled over the range $0.18-0.22 \mathrm{~kg} \mathrm{Pu}$. At the start of the simulation, the reduction-stabilization final filter is empty, and no cleanouts occur over the 1 -month simulation. At the end of $48 \mathrm{~h}$, the final filter has a holdup of $\sim 0.0095 \mathrm{~kg} \mathrm{Pu}$. The product and scrap output from the screen is shown in Fig. A-11. Because the screen services four parallel calciner-reduction-stabilization stations and each line transfers a canister to the screen every $8 \mathrm{~h}$, the screen processes canisters at the rate of one every $2 \mathrm{~h}$. As seen from the figure, the product is. $\sim 2.91 \mathrm{~kg}$ pu/canister and the scrap n $0.25 \mathrm{~kg} \mathrm{Pu} /$ canister.

\section{REFERENCES}

1. E. A. Hakkila, D. D. Cobb, H. A. Dayem, R. J. Dietz, E. A. Kern, E. P. Schelonka, J. P. Shipley, D. B. Smith, R. H. Augustson, and J. W. Barnes, "Coordinated Safeguards for Materials Management in a Fuel Reprocessing Plant," Los Alamos Scientific Laboratory report LA-6881 (September 1977).

2. H. A. Dayem, D. D. Cobb, R. J. Dietz, E. A. Hakkila, E. A. Kern, J. P. Shipley, D. B. Smith, and D. F. Bowersox, "Coordinated Safeguards for Materials Management in a Nitrate-to-oxide Conversion Facility," Los Alamos Scientific Laboratory report LA-701l (April 1978).

3. J. P. Shipley, D. D. Cobb, R. J. Dietz, M. L. Evans, E. P. Schelonka, D. B. Smith, and R. B. Walton, "Coordinated Safeguards for Materials Management in a Mixed-oxide Fuel Facility," Los Alamos Scientific Laboratory report LA-6536 (February 1977).

4. D. D. Cobb and D. B. Smith, "Modeling and Simulation in the Design and Evaluation of Conceptual Safeguards Systems," Nucl. Mater. Manage. VI (III), 171-184 (1977).

5. Savannah River Laboratory document DPSTD-AFCT-77-10-TL (November 1977).

6. J. Kleijnen, Statistical Techniques in Simulation (Marcel Dekker, New York, 1974).

7. T. Naylor, J. L. Balintfy, D. S. Burdick, and $K$. Chu, computer simulation Techniques (John wiley Sons, New York, 1966).

8. A. Pritsker, The GASP IV Simulation Language (Wi ley-Interscience, hew York, 1976). 